\title{
Genome-wide analysis of the serine carboxypeptidase-like protein family in Triticum aestivum reveals TaSCPL184-6D is involved in abiotic stress response
}

Xiaomin Xu' ${ }^{1 \dagger}$, Lili Zhang ${ }^{1 \dagger}$, Wan Zhao', Liang Fu², Yuxuan Han ${ }^{1}$, Keke Wang ${ }^{1}$, Luyu Yan ${ }^{3}$, Ye $\mathrm{Li}^{3}$, Xiao-Hong Zhang ${ }^{3^{*}}$ and Dong-Hong Min ${ }^{1^{*}}$

\begin{abstract}
Background: The serine carboxypeptidase-like protein (SCPL) family plays a vital role in stress response, growth, development and pathogen defense. However, the identification and functional analysis of SCPL gene family members have not yet been performed in wheat.

Results: In this study, we identified a total of 210 candidate genes encoding SCPL proteins in wheat. According to their structural characteristics, it is possible to divide these members into three subfamilies: CPI, CPII and CPIII. We uncovered a total of 209 TaSCPL genes unevenly distributed across 21 wheat chromosomes, of which 65.7\% are present in triads. Gene duplication analysis showed that $\sim 10.5 \%$ and $\sim 64.8 \%$ of the TaSCPL genes are derived from tandem and segmental duplication events, respectively. Moreover, the Ka/Ks ratios between duplicated TaSCPL gene pairs were lower than 0.6 , which suggests the action of strong purifying selection. Gene structure analysis showed that most of the TaSCPL genes contain multiple introns and that the motifs present in each subfamily are relatively conserved. Our analysis on cis-acting elements showed that the promoter sequences of TaSCPL genes are enriched in drought-, ABA- and MeJA-responsive elements. In addition, we studied the expression profiles of TaSCPL genes in different tissues at different developmental stages. We then evaluated the expression levels of four TaSCPL genes by qRT-PCR, and selected TaSCPL184-6D for further downstream analysis. The results showed an enhanced drought and salt tolerance among TaSCPL184-6D transgenic Arabidopsis plants, and that the overexpression of the gene increased proline and decreased malondialdehyde levels, which might help plants adapting to adverse environments. Our results provide comprehensive analyses of wheat SCPL genes that might work as a reference for future studies aimed at improving drought and salt tolerance in wheat.
\end{abstract}

\footnotetext{
*Correspondence: zhxh2493@126.com; mdh2493@126.com

†Xiaomin Xu and Lili Zhang contributed equally to this work.

${ }^{3}$ State Key Laboratory of Crop Stress Biology for Arid Areas and College of Life Sciences, Northwest A\&F University, Yangling, Shaanxi, China

${ }^{1}$ State Key Laboratory of Crop Stress Biology for Arid Areas and College of Agronomy, Northwest A\&F University, Yangling, Shaanxi, China

Full list of author information is available at the end of the article
}

(c) The Author(s). 2021 Open Access This article is licensed under a Creative Commons Attribution 4.0 International License, which permits use, sharing, adaptation, distribution and reproduction in any medium or format, as long as you give appropriate credit to the original author(s) and the source, provide a link to the Creative Commons licence, and indicate if changes were made. The images or other third party material in this article are included in the article's Creative Commons licence, unless indicated otherwise in a credit line to the material. If material is not included in the article's Creative Commons licence and your intended use is not permitted by statutory regulation or exceeds the permitted use, you will need to obtain permission directly from the copyright holder. To view a copy of this licence, visit http://creativecommons.org/licenses/by/4.0/ The Creative Commons Public Domain Dedication waiver (http://creativecommons.org/publicdomain/zero/1.0/) applies to the data made available in this article, unless otherwise stated in a credit line to the data. 
Conclusions: We conducte a comprehensive bioinformatic analysis of the TaSCPL gene family in wheat, which revealing the potential roles of TASCPL genes in abiotic stress. Our analysis also provides useful resources for improving the resistance of wheat.

Keywords: Serine carboxypeptidases-like protein, Genome-wide analysis, Drought stress, Salt stress, Wheat

\section{Background}

Wheat (Triticum aestivum) is one of the most vital crops in the world, contributing a large amount of calories and protein to the global human diet $[1,2]$. However, a variety of abiotic stresses seriously threaten the safety of wheat production. More than $50 \%$ of the world's wheat producing areas are affected by drought stress [3], which is the main abiotic factor limiting the productivity of wheat in arid and semi-arid regions [4]. Moreover, drought and heat stress often occur simultaneously at sensitive growth stages reducing wheat yield by reducing the number or weight of grains [5]. With the global climate changes, the occurrence and severity of these events are also likely to increase [5]. In addition, out of 230 million hectares of irrigated land worldwide, 45 million hectares (19.5\%) are threatened by salinization [6]. Soil salinization leads to reduced absorption of water and nutrients by plants [7], resulting in ion toxicity and oxidative damage to cells, thereby affecting their growth $[8,9]$. In major wheat producing areas, the accumulation of lead is often accompanied by cadmium contamination [10]. Low concentration of cadmium in soil can inhibit normal cell division, reduce photosynthesis and damage the activity of antioxidant enzymes [11, 12], seriously threatening the yield and safety of crops. Therefore, mining stress related genes and identifying their functions are of great significance for the cultivation of stress-resistant wheat varieties. Studies have shown that $S C P L$ genes play an important role in crop stress resistance. Therefore, it is of great significance to study the $S C P L$ genes in wheat.

The SCPL genes belong to the S10 subfamily of the SC family $[13,14]$, which includes a highly conserved $\alpha / \beta$ hydrolase tertiary structure [15-18]. SCPL proteins contain a conserved triplet consisting of three amino acid residues: a serine, an aspartate and a histidine (Ser-AspHis) $[17,18]$. These three amino acid residues are located in different positions within the primary structure but in relative proximity to one another, relying on the folding of the polypeptide chains in order to form the conserved triplet in the tertiary structure [19]. This enables the SCPL proteins to bind to the substrate and cleave the carboxy terminal peptide bond of its protein or peptide substrate [20]. In addition, SCPL proteins have an oxygen ion hole that participates in the stabilization of the substrate-enzyme intermediate during the hydrolysis process [17]. Most SCPL proteins share common structural features, including four evolutionarily conserved domains that are involved in substrate binding and catalysis, a signal peptide sequence for intracellular transport or secretion, and multiple Nlinked glycosylation sites [21, 22]. SCPL proteins are active under acidic $\mathrm{pH}$ conditions [13] and react during the proteolysis process [23-26].

The SCPL gene family has associated with biotic and abiotic stress responses. A type I SCP gene was identified in tomato (Lycopersicon esculentum Mill.) as one of the "late wound-inducible genes" based on its induced expression by wounding, systemin and methyl jasmonate (MeJA) [27]. The gene OsBISCPL1 was significantly overexpressed in rice leaves that were treated with defense-related signaling molecules, such as salicylic acid (SA) and jasmonic acid (JA), or infected with magnaporthe grisea [28]. In addition, Arabidopsis plants overexpressing OsBISCPL1 also showed an increased tolerance to oxidative stress, indicating that the gene may be involved in the regulation of defense responses against oxidative stress and pathogen infection [28]. In Arabidopsis thaliana, SNG1 and SNG2 act as acyltransferases and participate in the biosynthesis of sinapic acid esters, which has ultraviolet protection and antioxidant effects [29-32]. In addition, when respond to a variety of abiotic stresses, including drought, salinity, light, nitrogen and phosphorus deficiency, and suboptimal or supra-optimal temperatures, anthocyanins are also commonly induced in plants [33-39]. The roles of anthocyanins in abiotic stress include stress signaling [40, 41], photoprotection [42, 43], ROS quenching [44, 45]. In Arabidopsis, the gene AT2G23000 encode a sinapoylGlc:anthocyanin acyltransferase that is required for the synthesis of sinapoylated anthocyanins [46]. And both the serine carboxypeptidase-like 18 and the serine carboxypeptidase-like 18 isoform $\mathrm{X} 3$ are presumed to be involved in the biosynthesis of sinapoyl anthocyanin in Dendrobium officinale [47]. Finally, SCPL genes are also known to participate in the mobilization of storage proteins during seed germination [26, 48], the transformation of brassinolide signals $[28,49]$, the metabolism of herbicides [50], and to influence malting quality [51].

Whole-genome analysis of the SCPL gene family has been previously performed on a variety of plants. These studies have allowed the identification of 71 putative SCPL genes in rice (O. sativa), 54 in Arabidopsis (A. thalianna), 57 in poplar and 47 in the tea plant (Camellia 
sinensis) [52-54]. Here, we conducted a comprehensive genome-wide analysis of SCPL gene family in wheat and identified a total of 210 SCPL genes. In order to shed light on SCPL genes evolution and function, we performed a phylogenetic analysis and identified their physical location in different chromosomes, orthologous relationships, gene structure and tissue-specific expression patterns. The insights provided in this study will contribute to a better understanding on the evolution of SCPL genes and their role in the regulation of growth, development and responses to abiotic stress in wheat plants.

\section{Results}

\section{Identification of wheat SCPL genes}

The process flow of this study is shown in Additional file 1: Figure S1. A total of 210 candidate SCPL genes were identified in wheat (Fig. 1). For convenience, these genes were termed TaSCPL1-1A through TaSCPL210-Un following their respective chromosomal locations. Even though these genes all have conserved SCPL protein domains, their size and physicochemical properties vary greatly. Detailed information on these candidate genes is summarized in Additional file 9: Table S1.

The transcripts (including the UTR and the CDS) of 210 TaSCPL genes ranged from $300 \mathrm{bp}$ (TaSCPL44-2B) to $4553 \mathrm{bp}$ (TaSCPL124-4D), with an average length of $1636 \mathrm{bp}$. The number of amino acids ranged from 99 (TaSCPL44-2B) to 563 amino acids (TaSCPL62-2D), and averaged 446. Furthermore, the molecular weight of the TaSCPL genes ranged from $11.42 \mathrm{kDa}$ (TaSCPL44-2B) to $61.89 \mathrm{kDa}$ (TaSCPL62-2D) with an average weight of $49.25 \mathrm{kDa}$. The isoelectric point $(\mathrm{pI})$ values of these genes ranged from 4.64 (TaSCPL159-5D) to 9.44 (TaSCPL182-6B), with 80\% members (168/210) exhibiting acidic $\mathrm{pI}$ values.

\section{Phylogenetic relationships and classification of TaSCPL proteins}

We constructed a phylogenetic tree on the SCPL proteins from wheat, rice and Arabidopsis in order to explore the evolutionary relationships among these proteins in the different species (Fig. 1). According to the structural features and the classification of the SCPL proteins in rice and Arabidopsis from previous studies [52], it was possible to divide the TaSCPL proteins into three distinct subfamilies, namely the Carboxypeptidase I (CPI), Carboxypeptidase II (CPII) and Carboxypeptidase III (CPIII). A higher number of proteins were distributed in the CPI and CPII subfamilies in the three species (Fig. 2). In the specific case of wheat, we found that $48.1 \%(101 / 210), 35.2 \%(74 / 210)$ and $16.7 \%(35 / 210)$ of the SCPL proteins were located in the CPII, CPI and CPIII subfamilies, respectively. As expected, the SCPL proteins within the same species tend to cluster on the same branch.

\section{Chromosomal location and identification of homoeologs}

The precise locations of the TaSCPL genes on wheat chromosomes are listed in Additional file 9: Table S1. Most of these genes (209/210) were mapped to 21 chromosomes and revealed an uneven distribution in the genome, as shown in Fig. 3. There were a total of 27, 35, $27,38,45,16$ and 21 genes in chromosomes 1 to 7 , respectively. The number of TaSCPL genes per chromosome ranged from 5 to 20, with clusters being observed on chromosomes 5A, 5B and 5D. Specifically, chromosome $5 \mathrm{~A}$ contained the largest number of TaSCPL genes (20), followed by $4 \mathrm{~B}$ and $5 \mathrm{D}$ (14), while both chromosomes $6 \mathrm{~A}$ and $6 \mathrm{~B}$ had the lowest (5). This suggests that the duplication of TaSCPL genes might have occurred during the formation of chromosomes 2, 4 and 5 in wheat. These results suggest that the evolution of the TaSCPL gene family occurred independently within the different sub-genomes.

In this study, we analyzed homoeologous groups in detail (Table 1 and Additional file 10: Table S2) and found that $35.8 \%$ of all wheat genes (i.e. in the current version of the wheat genome) were present in triads (homoeologous groups of 3) (IWGSC, 2018). In contrast, we observed that $\sim 65.7 \%$ of the TaSCPL genes $(138 / 210)$ were present in triads. Moreover, the proportion of homoeologousspecific duplications in TaSCPL genes was lower than that in all wheat genes (5.2\% vs $5.7 \%)$. The loss of one homoeo$\log$ was less pronounced in the TaSCPL genes $(8.6 \%$ vs $13.2 \%)$, as was the existence of orphans or singletons $(9.5 \%$ vs $37.1 \%)$. Importantly, this high homoeolog retention rate can partly explain the existence of a higher number of TaSCPL genes in wheat than in both rice and Arabidopsis.

\section{Analyzing duplication events and natural selection}

To elucidate the evolutionary mechanisms behind the extension of TaSCPL genes, we evaluated tandem and segmental TaSCPL duplication events within the wheat genome. A total of 158 TaSCPL genes were located within syntenic blocks across different wheat chromosomes (Fig. 4 and Additional file 11: Table S3), forming 218 pairs of duplicated genes. We found that $54.4 \%$ (86/ 158) of the duplicated TaSCPL genes clustered on chromosomes 2, 4 and 5, which is consistent with the analysis described above. Statistical analysis showed that $~ 10.5 \%$ (22 out of 210) of the TaSCPL genes resulted from tandem duplication events (Additional file 11: Table S3), forming the following 11 pairs: TaSCPL7-1A/8-1A, TaSCPL19-1D/20-1D, TaSCPL26-1D/27-1D, TaSCPL282A/29-2A, TaSCPL31-2A/32-2A, TaSCPL37-2A/38-2A, TaSCPL47-2B/48-2B, TaSCPL58-2D/59-2D, TaSCPL974A/98-4A, TaSCPL114-4B/115-4B and TaSCPL150-5B/ 


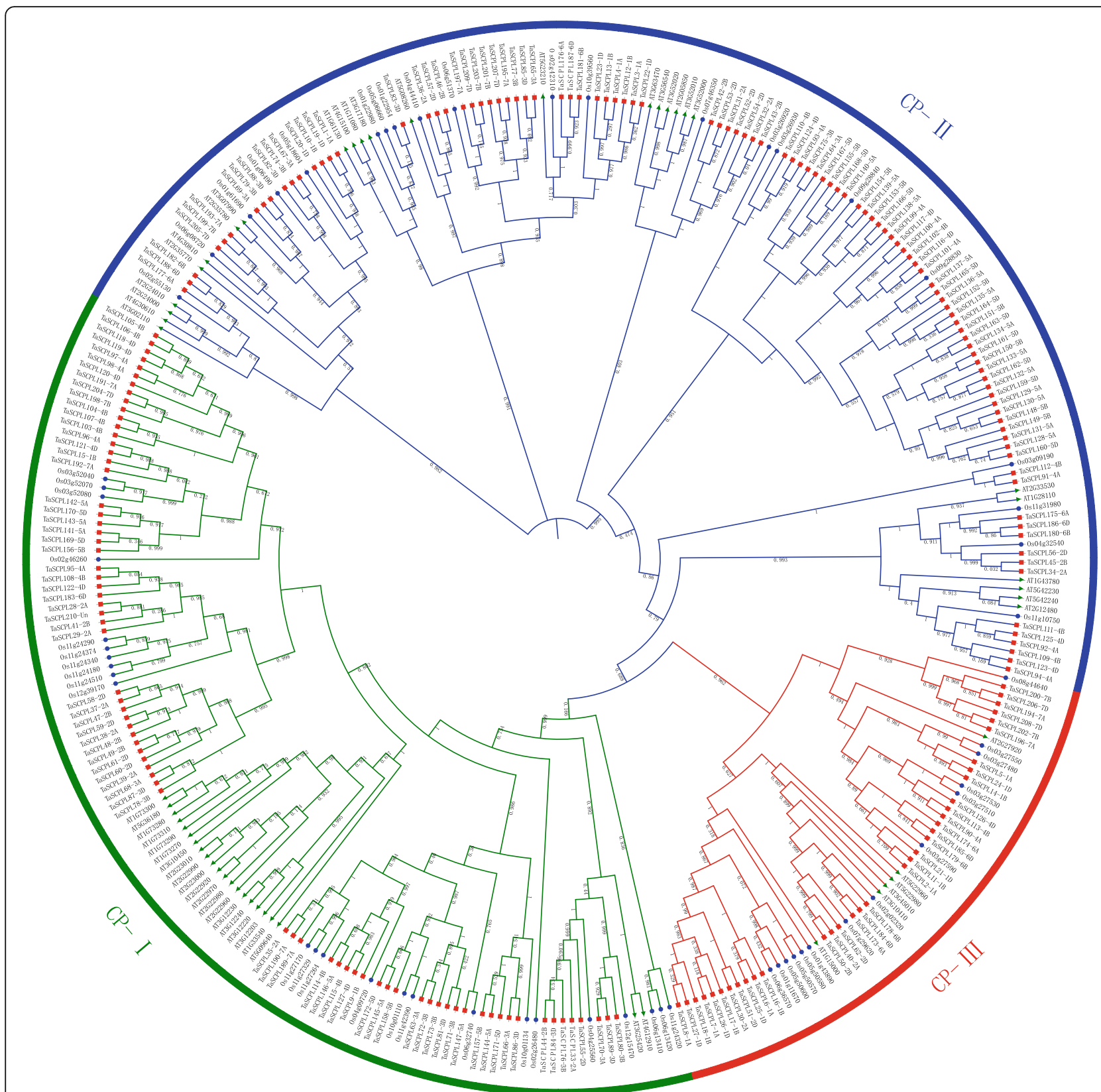

Fig. 1 A phylogenetic tree of the SCPL proteins in wheat, rice and Arabidopsis. The complete amino acid sequences were aligned using ClustalX and a Maximum-likelihood method with Fasttree. The tree was divided into three subfamilies according to Shimodaira-Hasegawa test value and the amount of evolutionary distance estimated. These subfamilies are denoted by the different colors: CPI (green), CPII (blue) and CPIII (red). The three crops were marked with different colored shapes: wheat (red squares), rice (blue circles) and Arabidopsis (green triangles)

151-5B. In addition, $64.8 \%$ (136 out of 210 ) of the TaSCPL genes were associated with WGD/segmental duplication, which thus seems to represent one of the main contributing factors behind the significant expansion of TaSCPL genes in the wheat genome.

To investigate the evolutionary forces acting on the $210 \mathrm{TaSCPL}$ genes, we estimated $\mathrm{Ka} / \mathrm{Ks}$ ratios for the different duplicated gene pairs (Additional file 11: Table $\mathrm{S} 3$ ). We found that the $\mathrm{Ka} / \mathrm{Ks}$ ratios of all TaSCPL duplicated gene pairs were lower than 0.6, ranging from 0.067 (TaSCPL193-7A/199-7B) to 0.56 (TaSCPL96-4A/ 121-4D) and averaging 0.27 . Moreover, the $\mathrm{Ka} / \mathrm{Ks}$ ratios of $33 \%(72 / 218)$ of the duplicated gene pairs ranged from 0.2 to $0.3,25 \%(54 / 218)$ ranged from 0.1 to 0.2 , and $24 \%(52 / 218)$ ranged from 0.3 to 0.4 (Fig. 5). The $\mathrm{Ka} / \mathrm{Ks}$ ratios of the $11 \mathrm{TaSCPL}$ tandem duplicated gene pairs ranged between 0.21 and 0.44 (Additional file 11: Table S3). These observations suggest that duplicated 


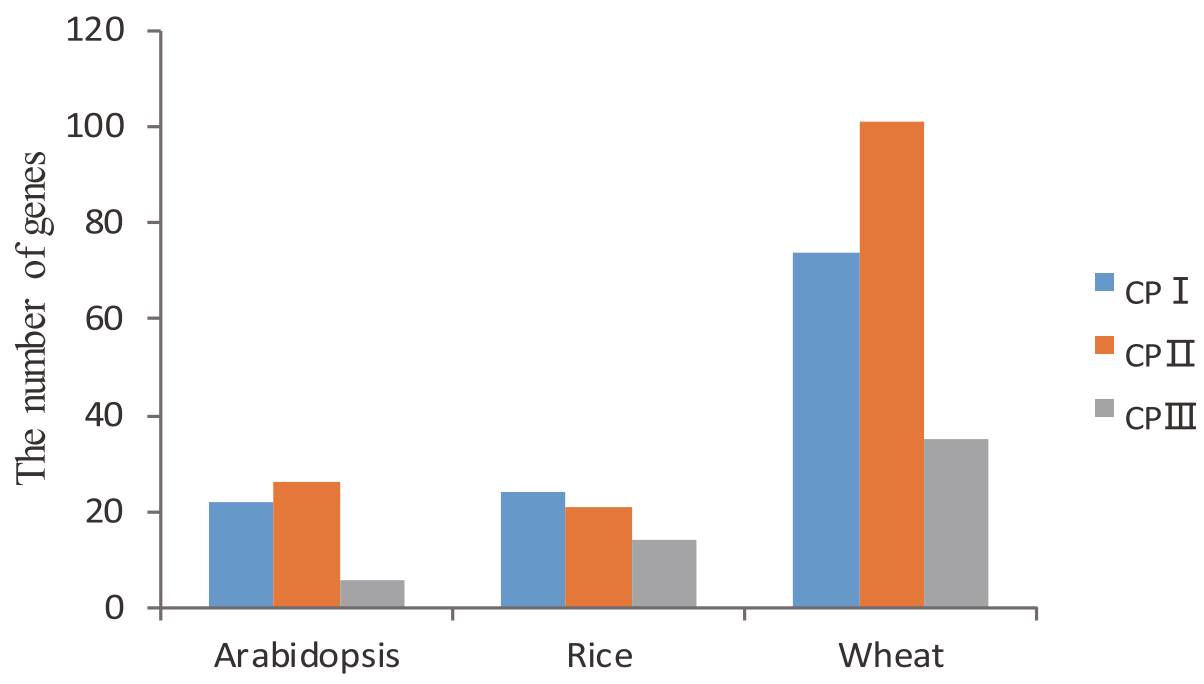

Fig. 2 The number of SCPL genes found in each subfamily of Arabidopsis, rice and wheat

TaSCPL genes have been evolving under purifying selection.

\section{Analyses on gene structure and conserved motifs}

In order to gain a deeper understanding on the diversity of TaSCPL gene structure and function, we built a phylogenetic tree using the $209 \mathrm{TaSCPL}$ protein sequences (except for TaSCPL147-5A, gene fragment loss may have occurred) (Additional file 2: Figure S2). We found that the structure of TaSCPL genes was relatively conserved within subfamilies, but differed between subfamilies. In the CPI subfamily, we found 4 genes with no introns, which ranged in number from 1 to 14 (with an average of 10). The number of introns of each gene in the CP II family ranged from 2 to 10 (with an average of 7 ), while only one gene did not contain intron. Finally, the number of introns per gene ranged from 1 to 12 (with an average of 7) in the CPIII subfamily, even though 10 out the 35 genes contained no intron.

We found that the motifs within TaSCPL proteins were generally well conserved, ranging in size from 11 to 80 amino acids in the 20 conserved motifs analyzed (Table 2). Specifically, the motifs of 1, 2, 3, 4, 5, 6, 8, 9 and 14 were present in almost all proteins (Additional file 2: Figure S2), while other motifs were specific to individual subfamilies in the phylogenetic tree. For example, motifs 10 and 12 were only detected in the CPI subfamily, motifs $11,13,17$ and 20 were specific to the CPII subfamily (motif 17 appeared in 3 CPI genes), and motifs 15 and 19 were solely found in the CPIII subfamily. These results indicated that TaSCPL proteins within the same subfamily often have similar motif composition. This is consistent with their relative phylogenetic relationships and suggests that the members of each subfamily are potentially associated with specific functions.

Interestingly, our phylogenetic analysis revealed that almost all of the proteins within the same subfamily with similar gene and conserved motif structures clustered on the same branch. For example, the CPIII subfamily was divided into three branches termed A, B and C (Fig. 6). The 18 proteins of branch $\mathrm{A}$ had similar conserved motifs, with motif 15 being present in all genes. The majority of genes in the A branch contained a total of 11 introns, excepting for TaSCPL113-4B (12 introns), TaSCPL14-1B, TaSCPL174-6A, TaSCPL179-6B and TaSCPL185-6D (with 10 introns each). Except for one intron found in TaSCPL18-1B, the remaining 10 genes within branch $B$ did not contain any introns. With the exception of TaSCPL17-1B (where a gene fragment loss may have occurred), the 10 members of the $B$ branch possessed very similar conserved motifs. The 6 genes on branch $\mathrm{C}$ included 8 introns and their respective proteins contained the same conserved motifs. These results suggest that similar evolutionary events may affect the structure and function of these genes.

\section{Identification of cis-elements in the promoter region of TaSCPL genes}

We analyzed the promoter sequences of all TaSCPL genes using PlantCARE and found a huge number of cis-acting elements (Fig. 7 and Additional file 12: Table S4). The results showed that the majority of the uncovered cis-acting elements were environmental stress responsive elements $(39.8 \%$; 4188/10513), followed by hormone-responsive elements (31.9\%; 3349/10513), light-responsive elements (19.3\%; 2025/10513), and plant growth-related elements (9.0\%; 951/10513) (Fig. 7a). Among the environmental stress responsive elements, 


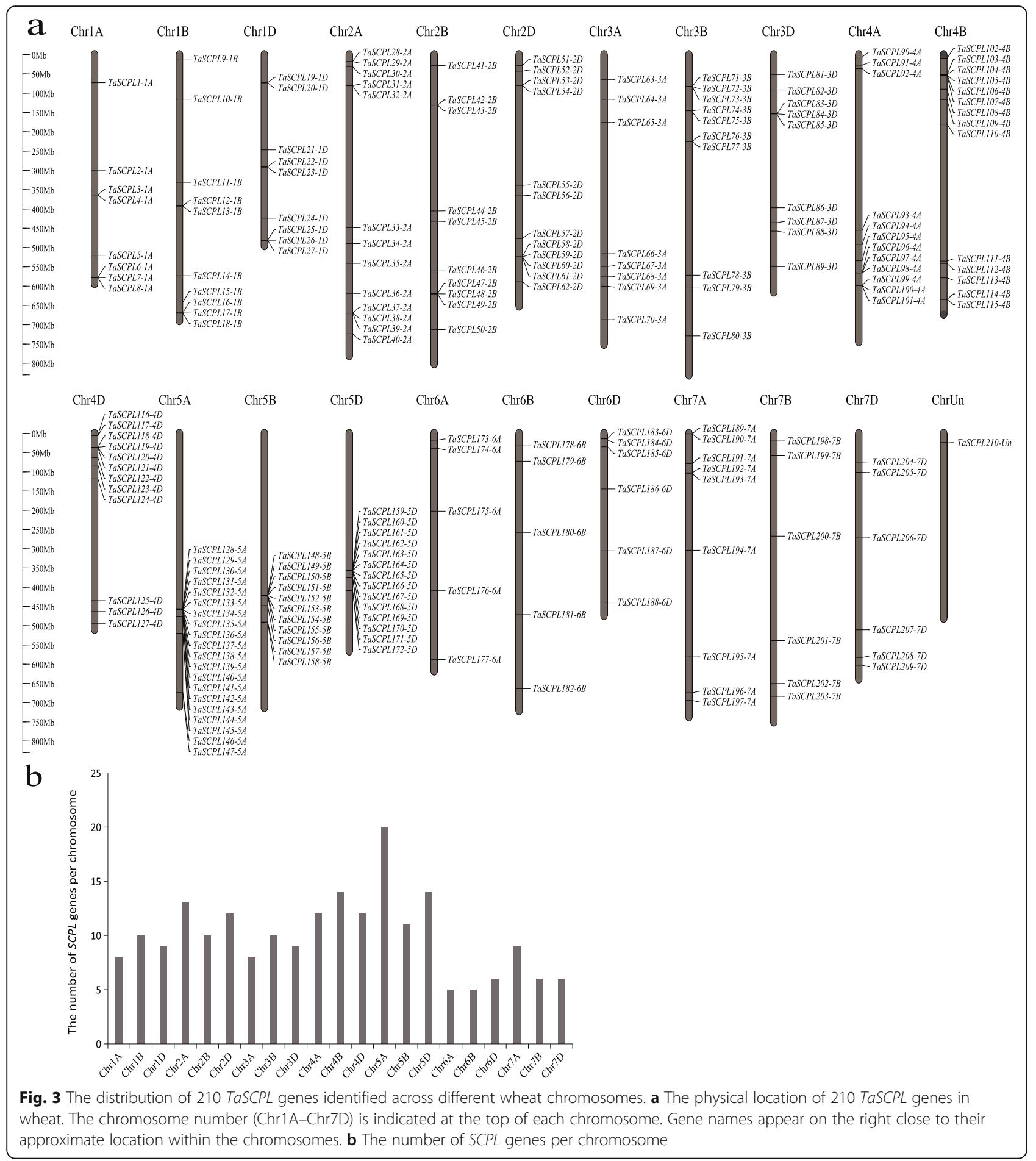

most were associated with drought response (45.4\%; $1900 / 4188)$, followed by wound (23.3\%; 976/4188) and stress (17.1\%; 716/4188) responses (Fig. 7b). Among the hormone-responsive elements, most constituted abscisic acid responsive elements $(56.3 \%$; 1886/3349), with a smaller proportion representing MeJA-responsive elements $(30.0 \% ; 1004 / 3349)$. These results demonstrated that TaSCPL genes are very likely associated with responses to abiotic stress, especially drought (Fig. 7c). In addition, among the identified elements that are related to plant growth, most were associated with rootspecific responsive elements (53.6\%; 510/951), suggesting 
Table 1 Homoeologous SCPL genes in wheat

\begin{tabular}{lllll}
\hline $\begin{array}{l}\text { Homoeologous } \\
\text { group (A:B:D) }\end{array}$ & All wheat genes & \multicolumn{2}{l}{ All wheat SCPL genes } \\
\cline { 3 - 5 } & & Number of groups & Number of genes & \% of genes \\
\hline $1: 1: 1$ & $35.8 \%$ & 46 & 11 & $65.7 \%$ \\
$1: 1: \mathrm{n} / 1: \mathrm{n}: 1 / \mathrm{n}: 1: 1, n>1$ & $5.7 \%$ & 5 & 18 & $5.2 \%$ \\
$1: 1: 0 / 1: 0: 1 / 0: 1: 1$ & $13.2 \%$ & 9 & 20 & $8.6 \%$ \\
Orphans/singletons & $37.1 \%$ & - & 23 & $11.0 \%$ \\
Other rations & $8.0 \%$ & 14 & 210 & $100 \%$ \\
\hline
\end{tabular}

that the TaSCPL gene family is also involved in root growth and development (Fig. 7d).

\section{Prediction of SSRs and miRNAs targeting TaSCPL genes}

We identified 105 candidate gene based simple sequence repeat (cg-SSR) motifs from different regions of 210 wheat SCPL genes. The detailed information of the simple sequence repeat (SSR) was given in the Additional file 13: Table S5. Among all the identified SSRs, the largest number were trinucleotides (46.7\%) followed by dinucleotides (40.0\%). Among them, the most frequently repeated motif was $(\mathrm{AGG} / \mathrm{CCT})_{5}$, which accounted for $7.6 \%$ of the total motifs, followed by (AG/ $\mathrm{CT})_{6}(5.7 \%)$. A total of 24 different types of SSR motifs were identified, of which 8 types of SSR motifs appeared only once, and the remaining 16 types appeared 2-17 times. The most frequent occurrence was AG/CT (16.2\%) followed by AC/GT (12.4\%). The sub-genome level analysis revealed that $35.2 \%$ motifs were distributed in both the A and D sub-genome, while $27.6 \%$ motifs were distributed on the $\mathrm{B}$ sub-genome. Cg-SSRs were distributed on all the 21 wheat chromosomes, but the number of them was different (Additional file 3: Figure S3); the largest number of cg-SSRs was found on chromosome $2 \mathrm{~B}(10.5 \%)$ and the smallest number $(0.9 \%)$ was found on chromosomes 1B, 1D and 6B. Furthermore, some research indicated that SSR motifs within the genic regions might also be involved in regulating the expression of corresponding genes $[55,56]$. Therefore, we designed 42 pairs of specific SSR primers (Additional file 14: Table S6), hoping to provide effective resources for trait mapping and crop breeding.

We also predicted putative microRNAs (miRNAs) targeting the TaSCPL genes by using the psRNATarget server [57]. The results showed that the TaSCPL genes were targeted by 4 different miRNAs (Additional file 15: Table S7) including tae-miR1130b-3p (MIMAT0035796), taemiR1122a (MIMAT0005357), tae-MIR1127a (MIMA T0005362) and tae-miR1134 (MIMAT0005369). Among them, tae-miR1130b-3p belongs to the MiR1130 family, while the others belong to the MiR1122 family. These two miRNA families were conserved in crops and respond to a variety of biotic and abiotic stresses [58, 59]. Therefore, this study can provide help for understanding the mechanism of wheat stress resistance.

\section{Analysis of TaSCPL gene expression in wheat}

In order to gain insight into the expression profiles of TaSCPL genes in different wheat tissues and periods, we downloaded expression data from the Wheat Expression Browser and generated a tissue-specific expression heatmap (Fig. 8 and Additional file 16: Table S8). Our analysis showed that $70.5 \%(148 / 210)$ of TaSCPL genes were expressed during one developmental stage, ranging from 1 to $8 \log _{2}$ tpm $\left(\log _{2}\right.$ tpm $\left._{\text {max }}\right)$ (Fig. 8 and Additional file 16: Table S8). The remaining 29.5\% (62/210) of TaSCPL genes showed very low expression levels in all developmental stages $\left(\log _{2} \mathrm{tpm}_{\max }<1\right)$ and were thus considered as unexpressed. Among the 74 genes of the CPI subfamily, $14.9 \%(11 / 74)$ were unexpressed, which could indicate that these genes underwent functional differentiation and redundancy. A variety of genes were highly expressed in the roots, leaves/shoots and spikes when comparing to grain. The CPII subfamily, which constitutes the largest clade, included a total of $42.6 \%$ $(43 / 101)$ of unexpressed genes, indicating that genes in this subfamily might have experienced a stronger degree of functional differentiation and redundancy. Importantly, most other genes were expressed in all tissues. A few genes were specifically expressed in spikes, including TaSCPL197-7A, TaSCPL203-7B and TaSCPL209-7D, while others were expressed in the leaves/shoots and spikes, including TaSCPL34-2A, TaSCPL45-2B and TaSCPL56-2D. In CPIII family, 22.9\% (8/35) of the genes showed very low to no transcripts. Some genes were expressed in various tissues, including six genes that displayed very high levels of transcription in the majority of tissues throughout wheat growth and developmental processes.

In order to evaluate the expression of TaSCPL genes under abiotic stress, we downloaded the relative expression abundances of all TaSCPL genes in 7-day-old seedling leaves under drought stress from the Wheat Expression Browser (Additional file 17: Table S9). RNA- 


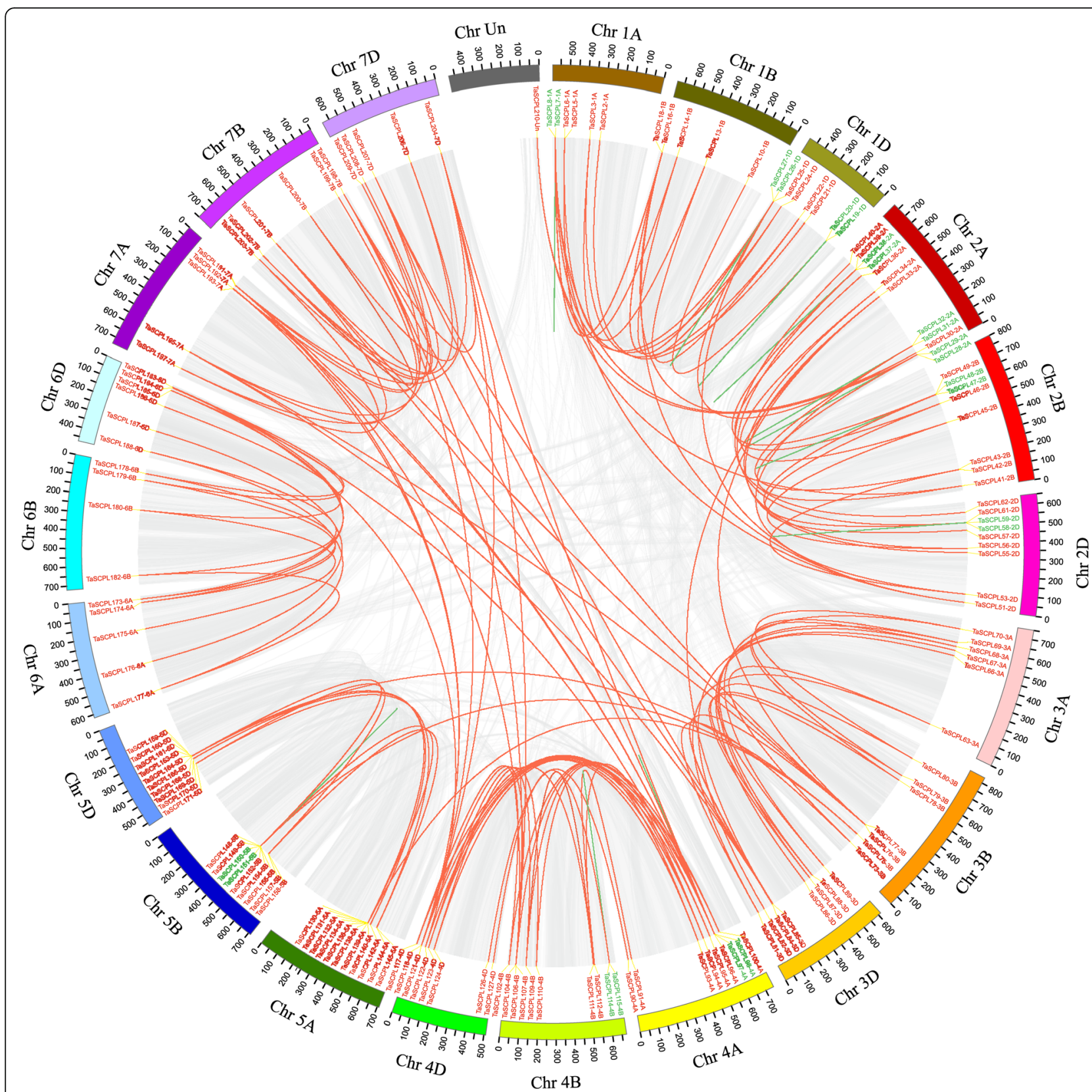

Fig. 4 Collinearity analysis SCPL gene family in the wheat genome. WGD/segmental and tandem duplications of TaSCPL genes were mapped to their respective locations in the wheat genome and represented in a circular diagram using Circos. The panel shows each of the 21 wheat chromosomes displayed in a circle. Gray regions indicate the synteny blocks within the wheat genome. The red lines connect segmental duplicated SCPL gene pairs (shown in red). The green lines connect tandem duplicated SCPL gene pairs (shown in green). The different chromosomes are represented by different colors with the chromosome number displayed outside the track

seq data suggested that a total of 57 TaSCPL genes were responsive to drought treatment (Fig. 9), of which $28.1 \%$ (16 out of 57) were up-regulated and $71.9 \%$ (41 out of 57) were down-regulated. These results indicated that abiotic stress can significantly induce multiple TaSCPL genes.

The expression patterns of four TaSCPL genes were then examined under drought, salt and ABA treatment using qRT-PCR (Fig. 10). The results obtained were consistent those of the RNA-seq experiment. The genes TaSCPL184-6D and TaSCPL68-3A showed a similarly up-regulated expression pattern under the three abiotic stress treatments. When compared to control samples, TaSCPL184-6D showed higher expression levels than TaSCPL68-3A under stress conditions. Specifically, TaSCPL184-6D showed the highest levels of expression 


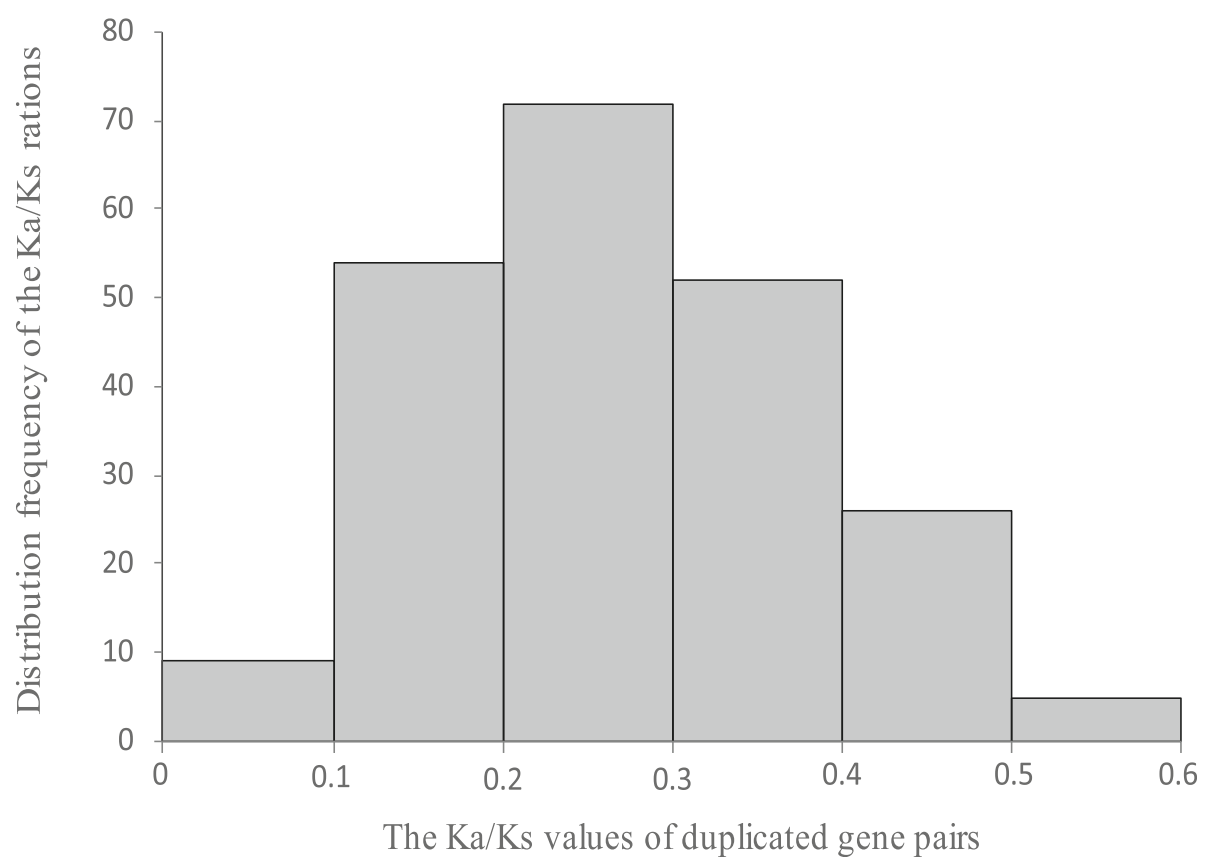

Fig. 5 A histogram of the distribution of pairwise Ka/Ks ratios for duplicated SCPL gene pairs

Table 2 List of the identified motifs in TaSCPL proteins

\begin{tabular}{lll}
\hline MOTIF & ID & WIDTH \\
\hline 1 & PZYKGRPFYIAGESYAGHYVP & 21 \\
2 & SWNKVANVJFLDSPAGVGFSY & 21 \\
3 & LTFATVRGAGHTVPEYQPERA & 21 \\
4 & YSGDHDSWPVTGTRAWIRSLGLPV & 25 \\
5 & KPLVLWLNGGPGCSS & 15 \\
6 & GVPFDQYTGYTVDEENGRALFYYFVEAE & 29 \\
7 & WGHGIISDZLYEAITKNCDFD & 21 \\
8 & VGDNRTALDAYVFLVKWFERF & 21 \\
9 & GPLINLKGYLVGNPLTD & 17 \\
10 & CRTYGYYLSYFWANBNMTRDALGIKKGTVGEWVR & 34 \\
11 & YLNRPDVQKALHANTTGW & 18 \\
12 & CNKDLPYTHDIPSSIKYHRNLTTRGYRAL & 29 \\
13 & NWKDSPASMLPTJKWLIEAGJRWW & 25 \\
14 & MEELGPFRVNPDGKT & 15 \\
15 & GVALGDSWISPEDFALSYAPLLYQVSRLDDNALDAANKLA & 80 \\
& ATVKEQJAAGQFAAAEKSWTDLLDFIDQQSNSVDMYNFLL & 11 \\
16 & WRPWHLDGQVA & 21 \\
17 & AVADQSGAKEADRITALPGQP & 15 \\
18 & AVADQSGAKEADRITALPGQP & 41 \\
20 & LKIIPKBVTWEECSDAVYEALVNDFMKPRIPEVDELLRYGV & 15 \\
\hline
\end{tabular}

after $1 \mathrm{~h}$ under drought and salt treatment and $24 \mathrm{~h}$ under the ABA treatment. TaSCPL68-3A reached its highest expression levels $1 \mathrm{~h}$ after the three treatments. Importantly, both TaSCPL63-3A and TaSCPL7-1A showed similarly down-regulated expression patterns under the three abiotic stress treatments. Finally, transcription analysis revealed that TaSCPL184-6D was significantly up-regulated under drought, salt and ABA treatments (Fig. 10), whereby it was chosen for downstream analyses.

\section{The overexpression of TaSCPL184-6D affects seed} germination under drought and $\mathrm{NaCl}$ stress in Arabidopsis In order to evaluate the functional role played by TaSCPL184-6D under drought or salt treatment, we used three homozygous T3 generation TaSCPL184-6Doverexpressing Arabidopsis lines (OE-1, OE-2 and OE$3)$. In order to examine seed germination, we used Murashige and Skoog (MS) mediums containing 8\% polyethylene glycol 6000 (PEG6000), 10\% PEG6000, 100 $\mathrm{mM} \mathrm{NaCl}$ and $150 \mathrm{mM} \mathrm{NaCl}$. We found no significant differences in the germination rate between wildtype (WT) and TaSCPL184-6D-overexpressing lines on a MS medium (Additional file 4: Figure S4, Additional file 5: Figure S5 and Additional file 19: Table S11). However, when PEG6000 was added to the MS medium, the germination of both WT and TaSCPL184-6D-overexpressing lines was inhibited, but the latter showed higher germination rates. The differences between WT and TaSCPL184-6D-overexpressing lines peaked 36 and $48 \mathrm{~h}$ 


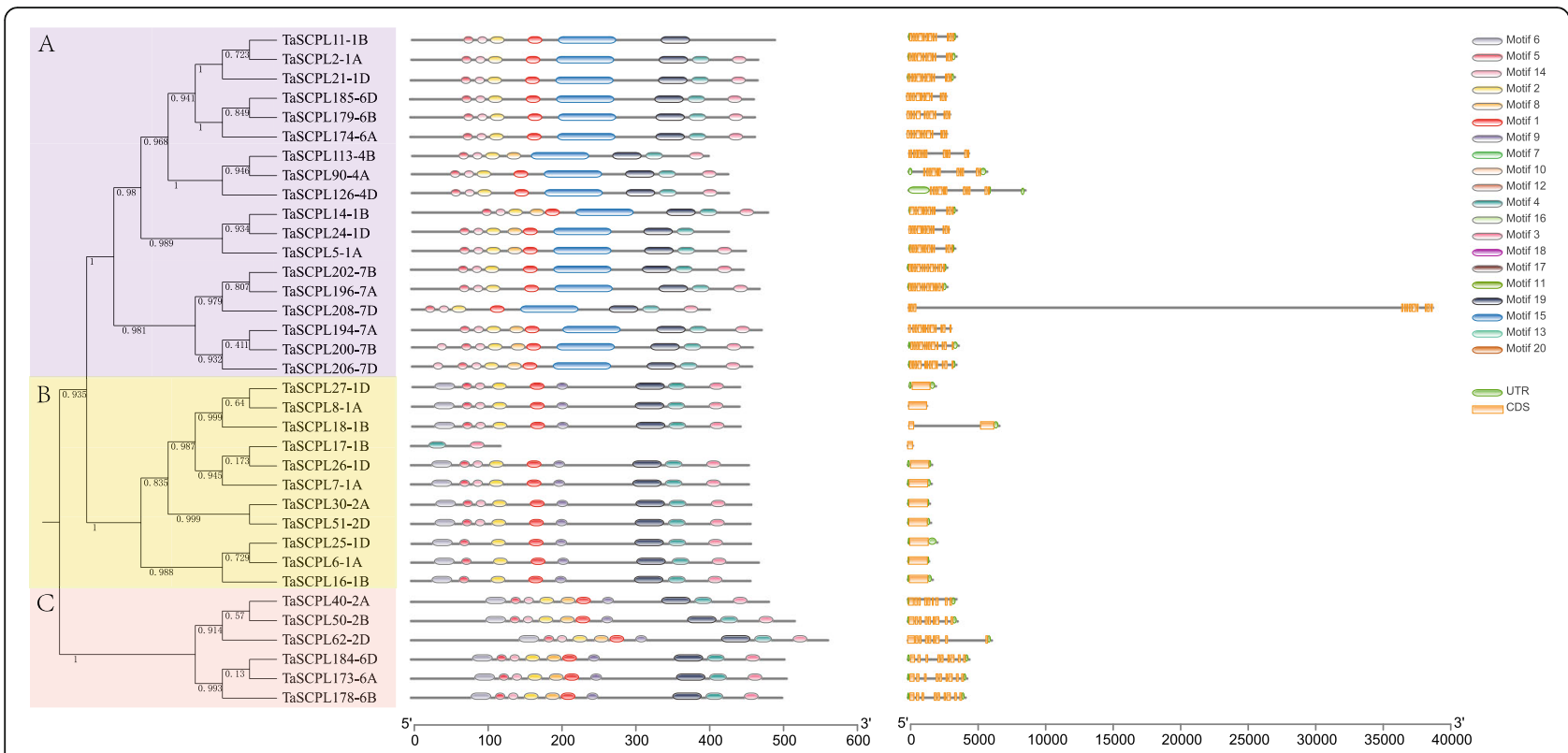

Fig. 6 Phylogenetic relationship, gene structure and conserved motifs analysis of 35 CPIII TaSCPL genes. The phylogenetic tree was constructed using Fasttree. Twenty putative motifs are indicated as colored boxes. Introns and exons are indicated by black lines and orange boxes, respectively. The lengths of introns, exons and proteins of each gene can be inferred using the scale displayed at the bottom

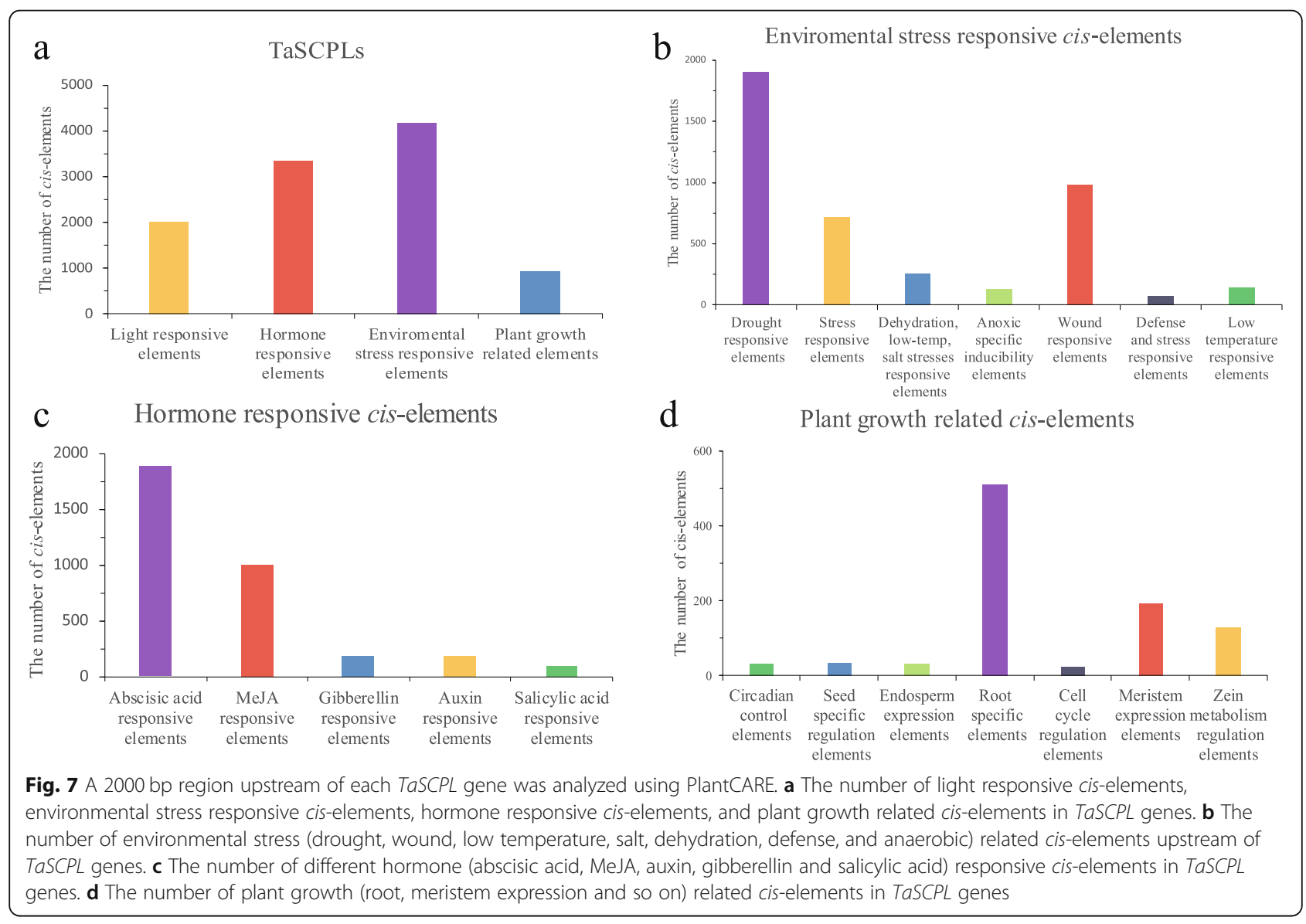




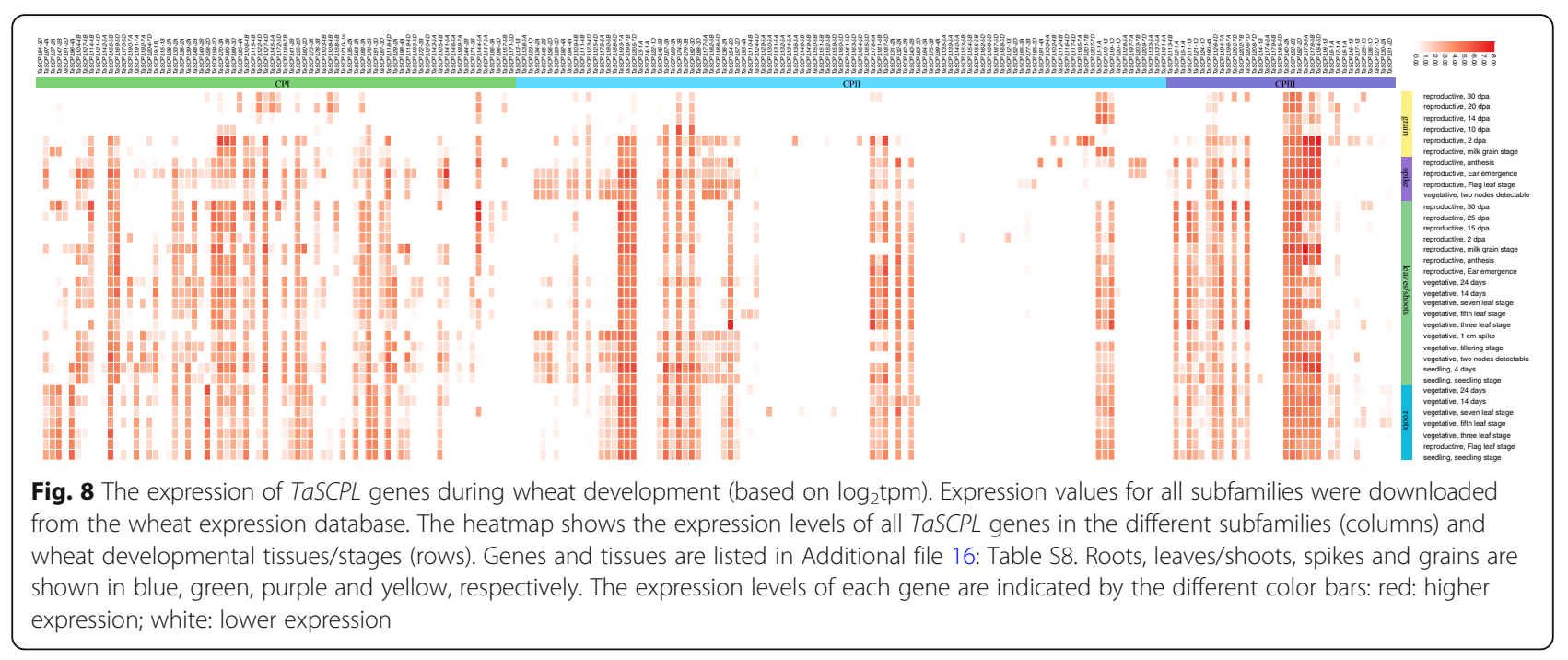

after treatment with 8 and 10\% PEG6000, respectively (Additional file 4: Figure S4). The germination rates of WT and TaSCPL184-6D-overexpressing lines was significantly also reduced on a MS medium containing $\mathrm{NaCl}$, and WT seeds showed a slower germination speed and rate compared to TaSCPL184-6D-overexpressing lines (Additional file 5: Figure S5), especially under the $150 \mathrm{mM} \mathrm{NaCl}$ treatment condition.

\section{TaSCPL184-6D conferred increased drought and salt tolerance in Arabidopsis}

To explore the function of TaSCPL184-6D under drought treatment, we conducted root length determination and seedling drought resistance studies. The 7day-old WT and TaSCPL184-6D-overexpressing lines growing uniformly on a MS medium were transferred to another MS medium containing 10\% PEG6000. We evaluated the phenotypic changes on these plants after 7 days of cultivation. No significant differences in root length and fresh weight were observed between WT and TaSCPL184-6D-overexpressing lines on the control MS medium, and plant growth followed normal trajectories (Additional file 6: Figure S6). However, under drought treatment with 10\% PEG6000, all TaSCPL184-6D-overexpressing lines showed longer root lengths and heavier fresh weights than WT plants. Moreover, these plants exhibited a better growth trajectory than WT (Additional file 6: Figure S6 and Additional file 20: Table S12). To evaluate changes in drought resistance of three-week-old WT and TaSCPL184-6D-overexpressing lines planted in the soil, we counted their respective survival rates and measured the amounts of proline (Pro) and malondialdehyde (MDA) that were present (Additional file 7: Figure S7 and Additional file 20: Table S12). Our results showed that, after drought treatment, both the survival rates and the amount of Pro in the
TaSCPL184-6D-overexpressing lines were significantly higher than that of WT. In contrast, the amount of MDA in TaSCPL184-6D-overexpressing lines was significantly lower than that of the WT.

We also conducted a further study on analyzing the effects salt treatment on TaSCPL184-6D-overexpressing lines. We found that all transgenic lines showed significantly longer root length and heavier fresh weight than the WT after $150 \mathrm{mM} \mathrm{NaCl}$ treatment (Additional file 6: Figure S6 and Additional file 20: Table S12). We also showed that the survival rates and the amount of Pro of the TaSCPL184-6D-overexpressing lines were significantly higher than those of WT when evaluating salt tolerance at the seedling stage. In contrast, we observed that the amount of MDA was significantly lower than that of the WT (Additional file 8: Figure S8 and Additional file 20: Table S12).

\section{Discussion}

The SCPL gene family plays an important functional role in plants. Whole-genome analysis of SCPL genes has been performed in a variety of plants and allowed for the identification of 71 putative SCPL genes in rice $(O$. sativa), 54 in Arabidopsis (A. thalianna), 57 in poplar and 47 in the tea plant (Camellia sinensis) [52-54]. However, no systemic analysis of the SCPL gene family has been reported in wheat. Therefore, this study aimed to conduct a comprehensive and systematic analysis of the wheat SCPL gene family, to explore the phylogeny and evolution of SCPL genes in wheat, and to investigate the phenotypes of Arabidopsis plants overexpressing the TaSCPL184-6D gene under drought and salt stress.

A total of 210 SCPL genes were identified in wheat and divided into three subfamilies (Fig. 1). The number of genes in the wheat $S C P L$ family is $\sim 3.9 \mathrm{x}, 3 \mathrm{x}, 3.7 \mathrm{x}$ and 4.5x higher than in Arabidopsis, rice, poplar and tea, 


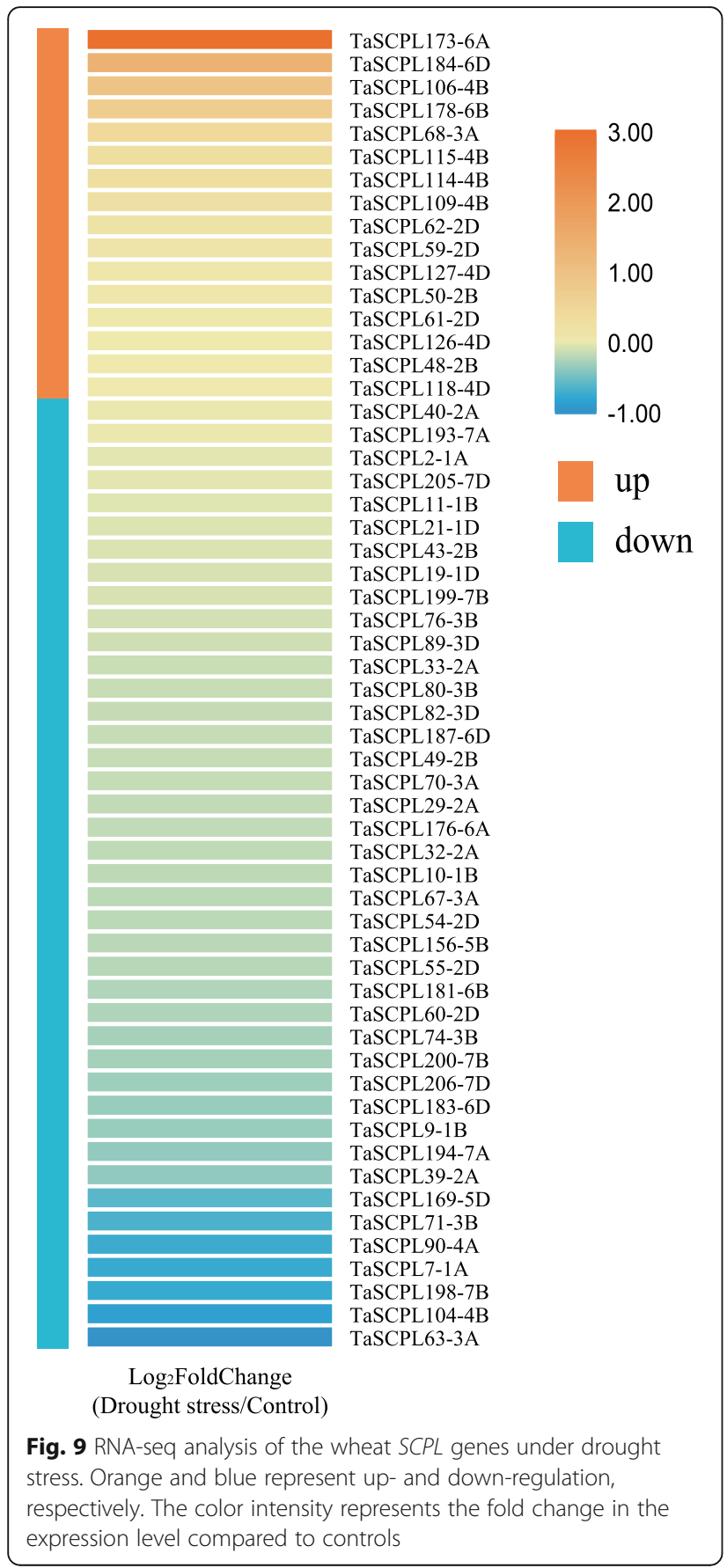

respectively. Approximately 65.7\% (138 out of 210) of the TaSCPL genes were present in triads, whereas this proportion is $\sim 35.8 \%$ across all wheat genes (IWGSC, 2018). Therefore, the high homologue retention rate could partly explain why the number of SCPL genes is higher in wheat than in other species. The phylogenetic analysis showed that wheat, tea, poplar and Arabidopsis have more genes in the CPI and CPII subfamilies. This indicates that the SCPLs in these different species might be undergoing conservative evolution [52-54].
The physical location of the SCPL genes in different species is unevenly distributed across the chromosomes. Specifically, 23.4, 19.3, 29.6 and $16.9 \%$ of the SCPL genes were located on Scaffold2990 in tea plants, 1.MAP in poplar, Chr.4 in Arabidopsis thaliana and Chr.11 in rice, respectively. However, some chromosomes contained only a single $S C P L$ gene in these species [52-54]. We showed that the distribution of SCPL genes in wheat is distributed across 21 chromosomes. There was a total of 20 SCPL genes on chromosome $5 \mathrm{~A}$, but only 5 on chromosomes $6 \mathrm{~A}$ and $6 \mathrm{~B}$. In addition, the 9 chromosomes of groups 2, 4 and 5 not only contained more genes $(56.2 \%$, $118 / 210)$ but also contained $54.4 \%(86 / 158)$ of duplicated genes, which are often observed in plant genomes and are produced by tandem and segmental duplications or polyploidization [60]. The expansion of the SCPL gene family in wheat mainly occurred through segmental duplications, which was consistent with the observations for the CsSCPL-IA subfamily in tea plants [54]. The Ka/ Ks values of the 218 duplicated gene pairs in the wheat $S C P L$ gene family were all lower than 0.6 , indicating that these genes are evolving under strong purifying selection.

Transcription factors (TFs) can regulate plant functions, including responses to hormones and environmental factors, cell differentiation and organ development, by regulating gene expression [61]. The analysis of cis-elements located in the promoter region of SCPL genes showed that the most hormone-responsive elements in wheat were the ABA- and the MeJA-responsive cis-elements. In contrast, the most relevant poplar cis-elements were the MeJAresponsive elements [53]. Among the environmental stress responsive elements, the most important were those related to drought in both wheat and poplar [53]. These results indicate that the SCPL gene family is likely involved in responses to drought stress through the $\mathrm{ABA}$ or the MeJA pathways.

In recent years, due to global climate change, a variety of abiotic stresses have become more frequent, in particular drought and salt stress. Abiotic stress affects plant growth and development by changing their physiology and metabolism, which ultimately leads to the decline of crop yield and quality $[62,63]$. In this study, we cloned the candidate TaSCPL184-6D wheat gene and overexpressed it in Arabidopsis thaliana in order to investigate its role in mediating plant responses to abiotic stress. We found that, when compared to the WT, transgenic Arabidopsis plants cultivated under drought or salt stress showed a higher germination and survival rates, as well as an increased root length. Moreover, Pro is involved in maintaining the dynamic plant balance in the face of adverse conditions [64]. Salt stress can cause oxidative and hyperosmotic damage to the cell membranes [65], and the amount of MDA can reflect the degree of 


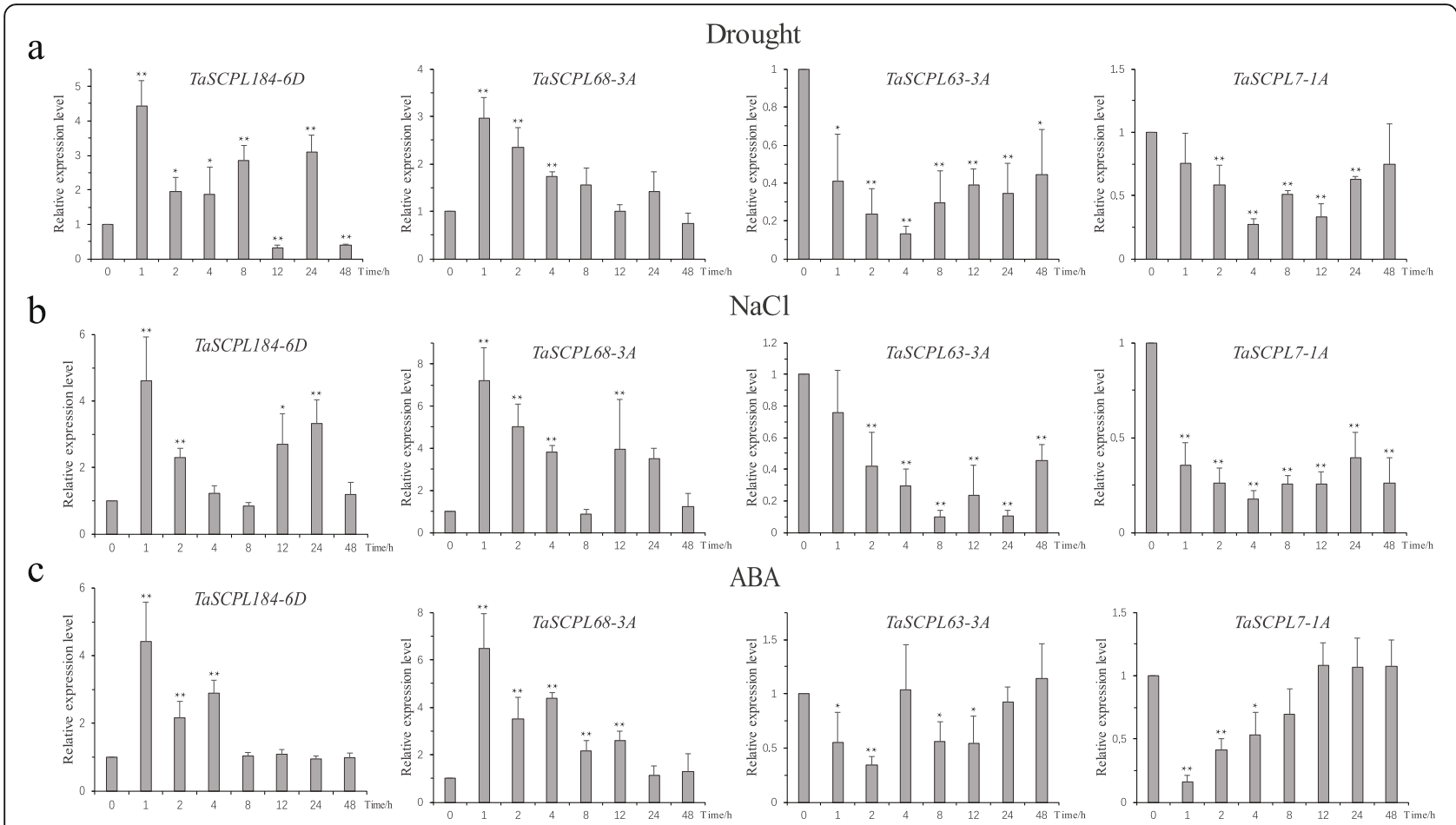

Fig. 10 The qRT-PCR analyses of four wheat TaSCPL genes under drought, NaCl and ABA treatments. The $\beta$-actin gene was used as an internal control. The mean and SD were calculated from three biological replicates. The $y$-axis represents the relative expression level. The $x$-axis indicates the duration of treatment: $0,1,2,4,8,12,24$, and $48 \mathrm{~h}$

damage suffered by plants. Under drought or salt treatments, we found a higher accumulation of Pro and a lower accumulation of MDA in TaSCPL184-6D transgenic Arabidopsis plants when compared to WT. This suggests that Pro might directly contribute to an enhanced tolerance of TaSCPL184-6D transgenic plants to drought and salt stress (Additional file 7: Figure S7 and Additional file 8: Figure S8). These physiological changes suggest that TaSCPL184-6D plays an active role in plant response to adverse environmental conditions.

\section{Conclusion}

We identified a total of 210 SCPL genes from the wheat genome, which were termed from TaSCPL1-1A to TaSCPL210-Un in accordance to their chromosomal positions, and performed comprehensive and systematic analysis on these genes. Our results showed that the TaSCPL184-6D gene, a member of the CPIII subfamily, improves the tolerance of Arabidopsis plants to drought and salt stresses. This study provides valuable insights for further understanding the evolutionary mechanisms behind wheat SCPL genes, and constitutes an important reference for the genetic improvement of wheat resistance.

\section{Methods}

Identification of wheat SCPL genes

We downloaded the protein sequences from the Ensembl Plants database (http://plants.ensembl.org/ index.html) [66] and obtained the Hidden Markov Model (HMM) profile of the SCPL conservative domain (PF00450) from Pfam (https://pfam.xfam.org) [67-69]. The wheat $S C P L$ gene family was subsequently identified in accordance to previous methods [70, 71]. The identified candidate SCPL genes were submitted to the NCBI protein Batch CD-search database (http://www.ncbi.nlm. nih.gov/Structure/bwrpsb/bwrpsb.cgi) [72] and the SMART database (https://smart.embl-heidelberg.de/) [73] in order to eliminate the genes lacking the conserved domain. After this verification, all of the candidate SCPL genes were identified in the wheat genome. The ExPASY website (https://www.expasy.org/) was used to predict the physicochemical parameters of the SCPL proteins, including molecular weight $(\mathrm{Mw})$ and theoretical pI [74].

\section{Phylogenetic analysis and classification of TaSCPL proteins}

A multiple sequence alignment of the SCPL sequences was generated using ClustalX [75] and removed Gap- 
only columns. The approximately-maximum-likelihood phylogenetic trees was constructed by the FastTree version 2.1.3 [76] using the JTT (Jones-Taylor-Thornton) model [77]. The "CAT" approximation [78] with 20 rate categories was used to account for the varying rates of evolution across sites. And the Shimodaira-Hasegawa test (1000 resamples) [79] was used to compute local support values. The trees were visualized using Figtree version 1.4.3.

\section{Chromosomal location and identification of homoeologs}

The SCPL genes were mapped against the 21 wheat chromosomes using positional information acquired from the Ensembl Plants database and the Mapchart software [80]. Homoeologous genes were identified using the phylogeny [81] and the Ensembl Plants database.

\section{Gene duplication and evolutionary selection analysis}

Segmental and tandem duplication events were determined according to previously described methods [71, 82]. Briefly, all TaSCPL proteins were searched using BLASTp (E-value $<10^{-10}$ ) and a pair of duplicated TaSCPL proteins were defined based on the following three criteria: 1) the alignment covered $>80 \%$ of the longer gene; 2) the aligned region had an identity $>80 \%$; 3 ) only one duplication event was counted for the genes which were tightly linked [83, 84]. Tandem repeat events were divided according to the chromosomal position of each duplicated gene. The Circos software was used to visualize the duplicated gene pairs in the T.astivum genome (Fig. 4) [85].

To assess the mode of selection acting on each TaSCPL duplicated gene pair, we calculated the rates of synonymous (Ks) and non-synonymous (Ka) substitutions, and their respective ratio, between two duplicated TaSCPL genes using the TBtools software [86]. Detailed information on the duplicated gene pairs can be found in Additional file 11: Table S3. A Ka/Ks ratio $>1$ is often associated with positive selection, a $\mathrm{Ka} / \mathrm{Ks}=1$ represents neutrality, and a $\mathrm{Ka} / \mathrm{Ks}$ ratio of $<1$ may represent purifying selection [87].

\section{Gene structure and conserved motifs analysis}

The exon/intron structure information for each gene was obtained from the Ensembl Plants database (http:// plants.ensembl.org/index.html). The exon-intron substructure map was produced using TBtools [86]. The conserved motifs of each SCPL protein were examined using the Multiple Expectation Maximization for Motif Elicitation program (MEME, http://meme-suite.org/ tools/meme) [88] and visualized by TBtools [86]. The number of motifs was set at 20 with motif width ranges from 6 to 100 (inclusive) amino acids. Any number of repetitions were considered during the verification, and the other parameters were default.

\section{Identification of cis-elements in the promoter region of TaSCPL genes}

In order to infer possible biological functions and the transcriptional regulation of the TaSCPL genes, the $2000 \mathrm{bp}$ region upstream of the translation initiation site was used as the promoter region in order to identify ciselements by submitting them to the PlantCARE database (http://bioinformatics.psb.ugent.be/webtools/plantcare/ $\mathrm{html} /$ ) [89].

Prediction of cg-SSRs and miRNAs targeting TaSCPL genes $\mathrm{Cg}$-SSRs were developed inside the genomic sequences of TaSCPL genes using MISA [90]. The screening parameters were: dinucleotides, trinucleotides, tetranucleotides, pentanucleotides and hexanucleotides were $\geq 6,5,5,4$ and 4 , respectively. The specific primers for SSRs were designed by Primer3 [91] and screened by e-PCR [92]. The potential MiRNAs targeting TaSCPL genes were predicted according to previously described methods [93]. Briefly, the psRNATarget server [57] was used to predict MiRNA, and MirBase 22.0 (http://www.mirbase.org/) [94] was used to query the specific information of miRNAs.

\section{Expression analysis of TaSCPL genes}

To study the expression of TaSCPL genes in different tissues and the response to drought, we obtained transcriptome data from the Wheat Expression browser (http://www.wheat-expression.com) [95]. $\log _{2}$ (transcripts per million) ( $\log _{2}$ tpm) values were used to estimate gene expression in different tissues (root, leaf/shoots, spikes and grains) and under drought treatment. The fold changes in expression levels relative to the control were used to generate a heatmap for $\mathrm{NaCl}$ treatment. The $\log _{2}$ tpm values of TaSCPL genes in different tissues and under drought stress treatment are shown in Additional file 16: Tables S8 and Additional file 17: Tables S9. The TBtools software was used to visualize the expression levels of the TaSCPL genes in the heatmap [86].

Plant materials, growth conditions and stress treatments Seeds from the wheat variety Chinese Spring were used for gene expression analysis. The treatment methods of plant materials refer to the previous literature and make some modifications $[96,97]$. The seeds grew in a greenhouse under a temperature of $22 / 20^{\circ} \mathrm{C}$ of day and night, and with a photoperiod of $16 \mathrm{~h}$ light $/ 8 \mathrm{~h}$ darkness. The 7-day-old seedlings underwent stress and hormone treatments. The seedlings were put on paper filters to perform drought stress, and were irrigated with a $100 \mathrm{mM} \mathrm{NaCl}$ solution to simulate salt treatment. For hormone treatments, the seedlings were exposed to 
solutions with $100 \mu \mathrm{M}$ ABA, $100 \mu \mathrm{M}$ MeJA, $100 \mu \mathrm{M}$ BR and $100 \mu \mathrm{M}$ GA. Seedling leaves from all treatments and controls were carefully harvested at $0,1,2,4,8,12,24$ and $48 \mathrm{~h}$, immediately frozen in liquid nitrogen and stored at $-80^{\circ} \mathrm{C}$ for subsequent analysis.

The Arabidopsis Col-0 plants were used for phenotypic assays. The growth conditions of the Arabidopsis plants were the same as those aforementioned for wheat. In order to obtain TaSCPL184-6D transgenic Arabidopsis, we linked the open reading frame (without the termination codon) of the TaSCPL184-6D gene to the pCAMBIA1302 vector. The recombinant plasmid was verified by sequencing, transformed into the Agrobacterium tumefaciens strain GV3101, and then transformed into Arabidopsis Columbia-0 (Col-0) according to a previously described flower immersion method [98]. The positive TaSCPL184-6D transgenic plants were identified by PCR and cultured to the $\mathrm{T}_{3}$ generation. The expression levels of TaSCPL184-6D in the $\mathrm{T}_{3}$ generation transgenic lines were determined by qRT-PCR, and the three lines with the highest expression levels were selected for further identification of stress resistance.

The WT and TaSCPL184-6D transgenic Arabidopsis were used to assess drought and salt tolerance. For germination analysis, the seeds of WT and TaSCPL184-6Doverexpressing lines were surface sterilized and sown on a MS medium containing PEG6000 (8 and 10\%) (m/v) and $\mathrm{NaCl}(100 \mathrm{mM}$ and $150 \mathrm{mM})$. Subsequently, 3 days after vernalization, the seeds were transferred to normal conditions for germination. When the radicle broke through the seed coat, the seed was considered as germinated. The germination rates were counted every $12 \mathrm{~h}$. For root length determination, 7-day-old uniformly germinated seeds were transferred to a MS media with $10 \%$ PEG6000 or $150 \mathrm{mM} \mathrm{NaCl}$. The root length was evaluated after treatment for 7 days. To assess drought tolerance in the soil, 3-week-old seedlings were kept dry for 2 weeks and then rewatered for 3 days. For salt treatment, the seedlings grown under normal conditions were irrigated with $100 \mathrm{mM} \mathrm{NaCl}$ solution for 7 days and then watered for another 3 days. We recorded the survival rates and performed three independent biological replicates.

\section{RNA extraction and quantitative real-time PCR}

Total RNA was isolated from wheat leaves treated under various stress conditions using the Trizol reagent (TaKaRa, Japan). The FastKing RT Kit (With gDNase) (TIANGEN, China) was used to remove the contamination of genomic DNA and perform cDNA synthesis following the manufacturer's instructions. Quantitative real-time PCR (qRT-PCR) was performed using the SuperReal PreMix Color (SYBR Green) (TIANGEN, China) and the QuantStudio 7 Flex Real-Time PCR system
(ThermoFisher, USA). The wheat $\beta$-actin gene (GenBank accession number AB181991.1) was used as an internal reference for all qRT-PCR analysis. We performed three independent replicates for each treatment. The relative expression levels of each gene was calculated based on the $2^{-\triangle C C T}$ value [99]. The specific primers used for qRT-PCR are listed in Additional file 18: Table S10.

\section{Measuring the amount of MDA and pro}

To measure the amount of Pro and MDA, 3-week-old seedlings of WT and transgenic Arabidopsis plants were subjected to drought for 2 weeks or salt stress for 1 week. The corresponding assay kit (Cominbio, Suzhou, China) was then used to measure the amount of Pro and MDA in the leaves. A total of three repetitions were implemented in each measurement.

\section{Statistical analysis}

The aforementioned experiments were repeated 3 times, independently, in order to obtain sufficient data to perform statistical analyses. The values are shown as mean \pm standard deviation (SD). An ANOVA test was used for statistical analysis. The significance levels were defined as $*(P<0.05)$; and $* *(P<0.01)$.

\section{Abbreviations}

SCPL: Serine carboxypeptidase-like protein; SA: Salicylic acid; JA: Jasmonic acid; MeJA: Methyl jasmonate; GA: Gibberellin; MS: Murashige and Skoog; Ka: Non-synonymous; Ks: Synonymous; SSR: Simple sequence repeat; Pro: Proline; MDA: Malondialdehyde; PEG6000: Polyethylene glycol 6000; Mw: Molecular weight; pl: Isoelectric point; SD: Standard deviation

\section{Supplementary Information}

The online version contains supplementary material available at https://doi. org/10.1186/s12864-021-07647-6.

Additional file 1: Figure S1. The research process of this study.

Additional file 2: Figure S2. Phylogenetic relationship, gene structure and conserved motifs analysis of 209 TaSCPL genes.

Additional file 3: Figure S3. The number of SSRs per chromosome.

Additional file 4: Figure S4. The overexpression of TASCPL184-6D increased the germination rate of seeds under PEG6000 treatment. a The phenotypes of WT and TaSCPL 184-6D transgenic Arabidopsis seeds under 8 and 10\% PEG6000 treatments. b The germination rates of WT and TaSCPL184-6D transgenic Arabidopsis seeds at different time points on MS medium. c The germination rates under 8\% PEG6000 treatment. d The germination rates under $10 \%$ PEG6000 treatment. A total of three biological replicates were performed. The error bars indicate the standard deviation (SD) of the three replicates.

Additional file 5: Figure S5. The overexpression of TASCPL184-6D increased the germination rate of seeds under $\mathrm{NaCl}$ treatment. a The phenotypes of WT and TaSCPL184-6D transgenic Arabidopsis seeds under $100 \mathrm{mM}$ and $150 \mathrm{mM} \mathrm{NaCl}$ treatments. b The germination rates of WT and TaSCPL 184-6D transgenic Arabidopsis seeds at different time points on MS medium. c The germination rates under $150 \mathrm{mM} \mathrm{NaCl}$ treatment. d The germination rates under 10\% PEG6000 treatment. A total of three biological replicates were performed. The error bars indicate the SD of the three replicates.

Additional file 6: Figure S6. The overexpression of TASCPL 184-6D enhanced the tolerance to drought and salt stresses in Arabidopsis. a 
Root length assays of wild-type and TaSCPL184-6D-overexpressing plants on a MS medium. b Root length assays under 10\% PEG6000 treatment. c Root length assays under $150 \mathrm{mM} \mathrm{NaCl}$ treatment. d Tool root length under 10\% PEG6000 treatment. e Tool root length under $150 \mathrm{mM} \mathrm{NaCl}$ treatment. f Fresh weight under 10\% PEG6000 treatment. g Fresh weight under $150 \mathrm{mM} \mathrm{NaCl}$ treatment.

Additional file 7: Figure S7. The overexpression of TaSCPL184-6D enhanced drought tolerance in Arabidopsis. a The drought tolerance phenotypes of WT and TaSCPL 184-6D transgenic Arabidopsis in soil. Three-week-old seedlings of WT and TaSCPL184-6D-overexpressing lines were dehydrated for 2 weeks and then rewatered for 3 days. b Statistical analysis of survival rates. $\mathbf{c}$ The amount of Pro. $\mathbf{d}$ The amount of MDA. Data is shown as the mean \pm SD of three independent replicates. Significant differences were observed using a Student' $s t$ test $\left({ }^{*} p<0.05,{ }^{* *} p<\right.$ 0.01).

Additional file 8: Figure S8. The overexpression of TaSCPL184-6D enhanced the tolerance to $\mathrm{NaCl}$ tolerance in Arabidopsis. a $\mathrm{NaCl}$ tolerance phenotypes of WT and TaSCPL184-6D transgenic Arabidopsis in soil. Three-week-old seedlings of WT and TaSCPL184-6D-overexpressing lines were stressed for 7 days and then rewatered for 3 days. b Statistical analysis of survival rates. $\mathbf{c}$ The amount of Pro. $\mathbf{d}$ The amount of MDA.

Additional file 9: Table S1. The characteristics of 210 wheat SCPL genes.

Additional file 10: Table S2. Homoeologous SCPL genes in wheat. Additional file 11: Table S3. The Ka/Ks ratios of duplicated SCPL gene pairs.

Additional file 12: Table S4. Cis-acting elements in the promoter region of TaSCPL genes.

Additional file 13: Table S5. The characteristics of 105 SSRs.

Additional file 14: Table S6. The information of SSR primers.

Additional file 15: Table S7. The detailed information of predicted miRNAs.

Additional file 16: Table S8. The $\log _{2} t p m$ values of all TaSCPL genes in the different subfamilies and wheat developmental tissues/stages.

Additional file 17: Table S9. The $\log _{2}$ tpm values of all TaSCPL genes under drought stress treatment.

Additional file 18: Table S10. The primers used in this study. Additional file 19: Table S11. The germination rates of seeds in transgenic Arabidopsis plants under PEG6000 and $\mathrm{NaCl}$ treatments.

Additional file 20: Table S12. Total root length, fresh weight, and the amount of PRO and MDA.

\section{Acknowledgements}

Not applicable.

\section{Authors' contributions}

DHM and XHZ conceived and designed the experiments. XX performed the experiments and wrote the paper. LZ contributed to data analysis. LF collected the previous studies. WZ and YH contributed to bioinformatics analysis. KW, LY and YL designed primers and performed the GRT-PCR. All authors have read and agreed to the published version of the manuscript.

\section{Funding}

This research was financially supported by the National Transgenic Key Project of the Chinese Ministry of Agriculture (2016ZX08002002-010), the National Key Research and Development Program of Wheat Molecular Design and Breeding (2016YFD0101802), and the Programme of Introducing Talents of Innovative Discipline to Universities (Project 111) from the State Administration of Foreign Experts Affairs (\#B18042) "Crop breeding for disease resistance and genetic improvement".

\section{Availability of data and materials}

All data generated or analyzed during this study are included within the article and its additional files. The phylogenetic data in our manuscript has been deposited into Treebase database with the access URL is http://purl. org/phylo/treebase/phylows/study/TB2:S27753.

\section{Declarations}

\section{Ethics approval and consent to participate}

The seeds of wheat (Chinese Spring) and Arabidopsis (Col-0) were both preserved in our experiment. And they were grown in the greenhouse of Northwest A\&F University. The research conducted in this study neither required approval from an ethics committee, nor involved any human or animal subjects. No specific permits were required for the described field studies. The location is not privately-owned or protected in any way, and the field studies did not involve endangered or protected species. We complied with the IUCN Policy Statement on Research Involving Species at Risk of Extinction and the Convention on the Trade in Endangered Species of Wild Fauna and Flora.

\section{Consent for publication}

Not applicable.

\section{Competing interests}

The authors declare that they have no competing interests.

\section{Author details}

${ }^{1}$ State Key Laboratory of Crop Stress Biology for Arid Areas and College of Agronomy, Northwest A\&F University, Yangling, Shaanxi, China. ${ }^{2}$ Xinxiang Academy of Agricultural Sciences of He'nan Province, Xinxiang, China. ${ }^{3}$ State Key Laboratory of Crop Stress Biology for Arid Areas and College of Life Sciences, Northwest A\&F University, Yangling, Shaanxi, China.

Received: 6 February 2021 Accepted: 21 April 2021

Published online: 15 May 2021

\section{References}

1. Veraverbeke WS, Delcour JA. Wheat protein composition and properties of wheat glutenin in relation to breadmaking functionality. Crit Rev Food Sci Nutr. 2002:42(3):179-208. https://doi.org/10.1080/10408690290825510.

2. Shiferaw B, Smale M, Braun HJ, Duveiller E, Reynolds M, Muricho G. Crops that feed the world 10. Past successes and future challenges to the role played by wheat in global food security. Food Security. 2013;5(3):291-317. https://doi.org/10.1007/s12571-013-0263-y.

3. Rajaram S. Prospects and promise of wheat breeding in the 21 st century. Euphytica. 2001;119(1-2):3-15. https://doi.org/10.1023/A:1017538304429.

4. Zadražnik T, Hollung K, Egge-Jacobsen W, Meglič V, Šuštar-Vozlič J. Differential proteomic analysis of drought stress response in leaves of common bean (Phaseolus vulgaris L.). J Proteome. 2013;78:254-72. https://doi.org/10.1016/j.jprot.2012.09.021.

5. Tricker PJ, ElHabti A, Schmidt J, Fleury D. The physiological and genetic basis of combined drought and heat tolerance in wheat. J Exp Bot. 2018; 69(13):3195-210. https://doi.org/10.1093/jxb/ery081.

6. Hanin M, Ebel C, Ngom M, Laplaze L, Masmoudi K. New insights on plant salt tolerance mechanisms and their potential use for breeding. Front Plant Sci. 2016;7:1787

7. Zheng Y, Xu X, Li Z, Yang X, Zhang C, Li F, et al. Differential responses of grain yield and quality to salinity between contrasting winter wheat cultivars. Seed Sci Biotechnol. 2009;3(2):40-3.

8. Tuteja N. Mechanisms of high salinity tolerance in plants. Methods Enzymol. 2007;428:419-38. https://doi.org/10.1016/S0076-6879(07)28024-3.

9. Gupta B, Huang B. Mechanism of salinity tolerance in plants: physiological, biochemical, and molecular characterization. Int J Genomics. 2014;2014(1): 701596.

10. Aprile A, Sabella E, Francia E, Milc J, Ronga D, Pecchioni N, et al. Combined effect of cadmium and Lead on durum wheat. Int J Mol Sci. 2019;20(23): 5891. https://doi.org/10.3390/ijms20235891.

11. Rizwan M, Ali S, Zia Ur Rehman M, Rinklebe J, DCW T, Bashir A, et al. Cadmium phytoremediation potential of Brassica crop species: A review. Sci Total Environ. 2018;631-632:1175-91.

12. Chen $D$, Chen $D$, Xue $R$, Long J, Lin $X$, Lin $Y$, et al. Effects of boron, silicon and their interactions on cadmium accumulation and toxicity in rice plants. J Hazard Mater. 2019;367:447-55. https://doi.org/10.1016/j.jhazmat.201 8.12.111.

13. Breddam K. Serine carboxy peptidases. A review. Carlsberg Res Commun. 1986;51(2):83-128. https://doi.org/10.1007/BF02907561. 
14. Mortensen UH, Olesen K, Breddam K. Carboxypeptidase C including carboxypeptidase Y. Handbook Proteolytic Enzymes. 2013:3408-12. https:// doi.org/10.1016/B978-0-12-382219-2.00753-5.

15. Milkowski C, Strack D. Serine carboxypeptidase-like acyltransferases. Phytochemistry. 2004;65(5):517-24. https://doi.org/10.1016/j.phytochem.2 003.12.018.

16. Ollis DL, Cheah E, Cygler M, Dijkstra B, Frolow F, Franken SM, et al. The alpha/beta hydrolase fold. Protein Eng. 1992;5(3):197-211. https://doi.org/1 0.1093/protein/5.3.197.

17. Holmquist M. Alpha/Beta-hydrolase fold enzymes: structures, functions and mechanisms. Curr Protein Pept Sci. 2000;1(2):209-35. https://doi.org/10.21 74/1389203003381405.

18. Fricker LD, Leiter EH. Peptides, enzymes and obesity: new insights from a 'dead' enzyme. Trends Biochem Sci. 1999;24(10):390-3. https://doi.org/10.1 016/S0968-0004(99)01448-6.

19. Liao DI, Remington SJ. Structure of wheat serine carboxypeptidase II at 3.5-a resolution. A new class of serine proteinase. J Biol Chem. 1990;265(12):652831. https://doi.org/10.1016/S0021-9258(19)39176-8.

20. Fraser CM, Rider LW, Chapple C. An expression and bioinformatics analysis of the Arabidopsis serine carboxypeptidase-like gene family. Plant Physiol. 2005;138(2):1136-48. https://doi.org/10.1104/pp.104.057950.

21. Agarwal V, Tikhonov A, Metlitskaya A, Severinov K, Nair SK. Structure and function of a serine carboxypeptidase adapted for degradation of the protein synthesis antibiotic microcin C7. Proc Natl Acad Sci U S A. 2012; 109(12):4425-30. https://doi.org/10.1073/pnas.1114224109.

22. Vendrell J, Avilés FX. Carboxypeptidases. Proteases New Perspect. 1999:1334. https://doi.org/10.1007/978-3-0348-8737-3_2.

23. Bamforth $\mathrm{CW}$, Martin $\mathrm{HL}$, Wainwright T. A role for carboxypeptidase in the solubilization of barley $\beta$-glucan. J I Brewing. 1979;85(6):334-8. https://doi. org/10.1002/j.2050-0416.1979.tb03937.x.

24. Bradley D. Isolation and characterization of a gene encoding a carboxypeptidase Y-like protein from Arabidopsis thaliana. Plant Physiol. 1992;98(4):1526-9. https://doi.org/10.1104/pp.98.4.1526.

25. Walker-Simmons M, Ryan CA. Isolation and properties of carboxypeptidase from leaves of wounded tomato plants. Phytochemistry. 1980;19(1):43-7. https://doi.org/10.1016/0031-9422(80)85010-2.

26. Washio K, Ishikawa K. Organ-specific and hormone-dependent expression of genes for serine carboxypeptidases during development and following germination of rice grains. Plant Physiol. 1994;105(4):1275-80. https://doi. org/10.1104/pp.105.4.1275.

27. Moura DS, Bergey DR, Ryan CA. Characterization and localization of a wound-inducible type I serine-carboxypeptidase from leaves of tomato plants (Lycopersicon esculentum mill.). Planta. 2001;212(2):222-30. https:// doi.org/10.1007/s004250000380.

28. Liu H, Wang $X$, Zhang H, Yang $Y$, Ge $X$, Song F. A rice serine carboxypeptidase-like gene OSBISCPL1 is involved in regulation of defense responses against biotic and oxidative stress. Gene. 2008;420(1):57-65. https://doi.org/10.1016/j.gene.2008.05.006.

29. Shirley AM, McMichael CM, Chapple C. The sng2 mutant of Arabidopsis is defective in the gene encoding the serine carboxypeptidase-like protein sinapoylglucose:choline sinapoyltransferase. Plant J. 2001;28(1):83-94. https://doi.org/10.1046/j.1365-313X.2001.01123.x.

30. Lehfeldt C, Shirley AM, Meyer K, Ruegger MO, Cusumano JC, Viitanen PV, et al. Cloning of the SNG1 gene of Arabidopsis reveals a role for a serine carboxypeptidase-like protein as an acyltransferase in secondary metabolism. Plant Cell. 2000;12(8):1295-306. https://doi.org/10.1105/tpc.12. 8.1295.

31. Lorenzen M, Racicot V, Strack D, Chapple C. Sinapic acid ester metabolism in wild type and a sinapoylglucose-accumulating mutant of arabidopsis. Plant Physiol. 1996;112(4):1625-30. https://doi.org/10.1104/pp.112.4.1625

32. Peyrot C, Mention MM, Brunissen F, Allais F. Sinapic acid esters: Octinoxate substitutes combining suitable UV protection and antioxidant activity. Antioxidants (Basel). 2020;9(9):782. https://doi.org/10.3390/antiox9090782.

33. Christie PJ, Alfenito MR, Walbot V. Impact of low-temperature stress on general phenylpropanoid and anthocyanin pathways: enhancement of transcript abundance and anthocyanin pigmentation in maize seedlings. Planta. 1994;194(4):541-9. https://doi.org/10.1007/BF00714468.

34. Garriga M, Retamales JB, Romero-Bravo S, Caligari PD, Lobos GA. Chlorophyll, anthocyanin, and gas exchange changes assessed by spectroradiometry in Fragaria chiloensis under salt stress. J Integr Plant Biol. 2014;56(5):505-15. https://doi.org/10.1111/jipb.12193.
35. Kovinich N, Kayanja G, Chanoca A, Riedl K, Otegui MS, Grotewold E. Not al anthocyanins are born equal: distinct patterns induced by stress in Arabidopsis. Planta. 2014;240(5):931-40. https://doi.org/10.1007/s00425014-2079-1.

36. Miki S, Wada KC, Takeno K. A possible role of an anthocyanin filter in lowintensity light stress-induced flowering in Perilla frutescens var. crispa. J Plant Physiol. 2015;175:157-62. https://doi.org/10.1016/j.jplph.2014.12.002.

37. Peng M, Hudson D, Schofield A, Tsao R, Yang R, Gu H, et al. Adaptation of Arabidopsis to nitrogen limitation involves induction of anthocyanin synthesis which is controlled by the NLA gene. J Exp Bot. 2008:59(11):293344. https://doi.org/10.1093/jxb/ern148.

38. Zhang $Y$, Zheng S, Liu Z, Wang L, Bi Y. Both HY5 and HYH are necessary regulators for low temperature-induced anthocyanin accumulation in Arabidopsis seedlings. J Plant Physiol. 2011;168(4):367-74. https://doi.org/1 0.1016/j.jplph.2010.07.025.

39. Olsen KM, Lea US, Slimestad R, Verheul M, Lillo C. Differential expression of four Arabidopsis PAL genes; PAL1 and PAL2 have functional specialization in abiotic environmental-triggered flavonoid synthesis. J Plant Physiol. 2008; 165(14):1491-9. https://doi.org/10.1016/j.jplph.2007.11.005.

40. Pourcel L, Irani NG, Koo AJ, Bohorquez-Restrepo A, Howe GA, Grotewold E. A chemical complementation approach reveals genes and interactions of flavonoids with other pathways. Plant J. 2013;74(3):383-97. https://doi.org/1 $0.1111 /$ tpj.12129.

41. Marko D, Puppel N, Tjaden Z, Jakobs S, Pahlke G. The substitution pattern of anthocyanidins affects different cellular signaling cascades regulating cell proliferation. Mol Nutr Food Res. 2004;48(4):318-25. https://doi.org/10.1002/ mnfr.200400034.

42. Hughes NM, Carpenter KL, Keidel TS, Miller CN, Waters MN, Smith WK. Photosynthetic costs and benefits of abaxial versus adaxial anthocyanins in Colocasia esculenta 'Mojito'. Planta. 2014;240(5):971-81. https://doi.org/10.1 007/s00425-014-2090-6.

43. Tattini M, Landi M, Brunetti C, Giordano C, Remorini D, Gould KS, et al. Epidermal coumaroyl anthocyanins protect sweet basil against excess light stress: multiple consequences of light attenuation. Physiol Plant. 2014;152(3): 585-98. https://doi.org/10.1111/ppl.12201.

44. Gould K, McKelvie J, Markham K. Do anthocyanins function as antioxidants in leaves? Imaging of $\mathrm{H}_{2} \mathrm{O} 2$ in red and green leaves after mechanical injury. Plant Cell Environ. 2002;25(10):1261-9. https://doi.org/10.1046/j.1365-3040.2 002.00905.x.

45. Nakabayashi R, Yonekura-Sakakibara K, Urano K, Suzuki M, Yamada Y, Nishizawa T, et al. Enhancement of oxidative and drought tolerance in Arabidopsis by overaccumulation of antioxidant flavonoids. Plant J. 2014; 77(3):367-79. https://doi.org/10.1111/tpj.12388.

46. Fraser CM, Thompson MG, Shirley AM, Ralph J, Schoenherr JA, Sinlapadech $\mathrm{T}$, et al. Related Arabidopsis serine carboxypeptidase-like sinapoylglucose acyltransferases display distinct but overlapping substrate specificities. Plant Physiol. 2007;144(4):1986-99. https://doi.org/10.1104/pp.107.098970.

47. Ren Z, Qiu F, Wang Y, Yu W, Liu C, Sun Y, et al. Network analysis of transcriptome and LC-MS reveals a possible biosynthesis pathway of anthocyanins in Dendrobium officinale. Biomed Res Int. 2020;2020:6512895.

48. Dal Degan F, Rocher A, Cameron-Mills V, von Wettstein D. The expression of serine carboxypeptidases during maturation and germination of the barley grain. Proc Natl Acad Sci U S A. 1994;91(17):8209-13. https://doi.org/10.1 073/pnas.91.17.8209

49. Li J, Lease KA, Tax FE, Walker JC. BRS1, a serine carboxypeptidase, regulates BRI1 signaling in Arabidopsis thaliana. Proc Natl Acad Sci U S A. 2001;98(10): 5916-21. https://doi.org/10.1073/pnas.091065998.

50. Wolf AE, Dietz KJ, Schröder P. Degradation of glutathione S-conjugates by a carboxypeptidase in the plant vacuole. FEBS Lett. 1996;384(1):31-4. https:// doi.org/10.1016/0014-5793(96)00272-4.

51. Potokina E, Prasad M, Malysheva L, Röder MS, Graner A. Expression genetics and haplotype analysis reveal cis regulation of serine carboxypeptidase I (Cxp1), a candidate gene for malting quality in barley (Hordeum vulgare L.). Funct Integr Genomics. 2006;6(1):25-35. https:/doi.org/10.1007/s10142-005-0008-x.

52. Feng Y, Yu C. Genome-wide comparative study of rice and Arabidopsis serine carboxypeptidase-like protein families. J Zhejiang Univ. 2009;35(1):115.

53. Zhu D, Chu W, Wang Y, Yan $H_{1}$ Chen Z, Xiang Y. Genome-wide identification, classification and expression analysis of the serine carboxypeptidase-like protein family in poplar. Physiol Plant. 2018;162(3): 333-52. https://doi.org/10.1111/ppl.12642. 
54. Ahmad MZ, Li P, She G, Xia E, Benedito VA, Wan XC, et al. Genome-wide analysis of serine carboxypeptidase-like acyltransferase gene family for evolution and characterization of enzymes involved in the biosynthesis of Galloylated Catechins in the tea plant (Camellia sinensis). Front Plant Sci. 2020;11:848. https://doi.org/10.3389/fpls.2020.00848.

55. Sharopova N. Plant simple sequence repeats: distribution, variation, and effects on gene expression. Genome. 2008;51(2):79-90. https://doi.org/1 0.1139/G07-110.

56. Zhang L, Zuo K, Zhang F, Cao Y, Wang J, Zhang Y, et al. Conservation of noncoding microsatellites in plants: implication for gene regulation. BMC Genomics. 2006;7(1):323. https://doi.org/10.1186/1471-2164-7-323.

57. Dai $X$, Zhuang Z, Zhao PX. psRNATarget: a plant small RNA target analysis server (2017 release). Nucleic Acids Res. 2018 Jul 2;46(W1):W49-54. https:// doi.org/10.1093/nar/gky316.

58. Han R, Jian C, LV J, Yan Y, Chi Q, Li Z, et al. Identification and characterization of microRNAs in the flag leaf and developing seed of wheat (Triticum aestivum L.). BMC Genomics. 2014;15:289.

59. Yao Y, Guo G, Ni Z, Sunkar R, Du J, Zhu JK, et al. Cloning and characterization of microRNAs from wheat (Triticum aestivum L.). Genome Biol. 2007:8(6):R96.

60. Zhang J. Evolution by gene duplication: an update. Trends Ecol Evol. 2003; 18(6):292-8. https://doi.org/10.1016/S0169-5347(03)00033-8.

61. Sukumari Nath $\vee$, Kumar Mishra A, Kumar A, Matoušek J, Jakše J. Revisiting the Role of Transcription Factors in Coordinating the Defense Response Against Citrus Bark Cracking Viroid Infection in Commercial Hop (Humulus lupulus L.). Viruses. 2019;11(5):419.

62. Maren E, Veatch-Blohm. Principles of Plant Genetics and Breeding. Crop Sci. 2007:47(4):1763

63. Gill SS, Tuteja N. Reactive oxygen species and antioxidant machinery in abiotic stress tolerance in crop plants. Plant Physiol Biochem. 2010;48(12): 909-30. https://doi.org/10.1016/j.plaphy.2010.08.016.

64. Székely G, Abrahám E, Cséplo A, Rigó G, Zsigmond L, Csiszár J, et al. Duplicated P5CS genes of Arabidopsis play distinct roles in stress regulation and developmental control of proline biosynthesis. Plant J. 2008:53(1):11-28. https://doi.org/10.1111/j.1365-313X.2007.03318.x.

65. Zhu JK. Abiotic stress signaling and responses in plants. Cell. 2016;167(2): 313-24. https://doi.org/10.1016/j.cell.2016.08.029.

66. Bolser DM, Staines DM, Perry E, Kersey PJ. Ensembl plants: integrating tools for visualizing, mining, and analyzing plant genomic data. Methods Mol Biol. 2017;1533:1-31. https://doi.org/10.1007/978-1-4939-6658-5_1.

67. Finn RD, Bateman A, Clements J, Coggill P, Eberhardt RY, Eddy SR, et al. Pfam: the protein families database. Nucleic Acids Res. 2014;42(Database issue):D222-30. https://doi.org/10.1093/nar/gkt1223.

68. Coggill P, Finn RD, Bateman A. Identifying protein domains with the Pfam database. Curr Protoc Bioinformatics. 2008:2:2-5.

69. Finn RD, Clements J, Eddy SR. HMMER web server: interactive sequence similarity searching. Nucleic Acids Res. 2011;39(suppl):W29-37. https://doi. org/10.1093/nar/gkr367.

70. Rao KP, Richa T, Kumar K, Raghuram B, Sinha AK. In silico analysis reveals 75 members of mitogen-activated protein kinase kinase kinase gene family in rice. DNA Res. 2010;17(3):139-53. https://doi.org/10.1093/dnares/dsq011.

71. Wang M, Yue H, Feng K, Deng P, Song W, Nie X. Genome-wide identification, phylogeny and expressional profiles of mitogen activated protein kinase kinase kinase (MAPKKK) gene family in bread wheat (Triticum aestivum L.). BMC Genomics. 2016;17(1):668.

72. Yang M, Derbyshire MK, Yamashita RA, Marchler-Bauer A. NCBI's conserved domain database and tools for protein domain analysis. Curr Protoc Bioinformatics. 2020;69(1):e90. https://doi.org/10.1002/cpbi.90.

73. Schultz J, Milpetz F, Bork P, Ponting CP. SMART, a simple modular architecture research tool: identification of signaling domains. Proc Natl Acad Sci U S A. 1998;95(11):5857-64. https://doi.org/10.1073/pnas.95.11. 5857.

74. Artimo P, Jonnalagedda M, Arnold K, Baratin D, Csardi G, de Castro E, et al. ExPASy: SIB bioinformatics resource portal. Nucleic Acids Res. 2012;40(W1): W597-603. https://doi.org/10.1093/nar/gks400

75. Larkin MA, Blackshields G, Brown NP, Chenna R, McGettigan PA, McWilliam $H$, et al. Clustal W and Clustal X version 2.0. Bioinformatics. 2007;23(21): 2947-8. https://doi.org/10.1093/bioinformatics/btm404.

76. Price MN, Dehal PS, Arkin AP. FastTree 2--approximately maximumlikelihood trees for large alignments. PLoS One. 2010;5(3):e9490. https://doi. org/10.1371/journal.pone.0009490.
77. Jones DT, Taylor WR, Thornton JM. The rapid generation of mutation data matrices from protein sequences. Comput Appl Biosci. 1992;8(3):275-82. https://doi.org/10.1093/bioinformatics/8.3.275.

78. Stamatakis A. Phylogenetic models of rate heterogeneity: a high performance computing perspective. Proceedings 20th IEEE International Parallel \& Distributed Processing Symposium. 2006. https://doi.org/10.1109/ IPDPS.2006.1639535

79. Shimodaira H, Hasegawa M. Multiple comparisons of loglikelihoods with applications to phylogenetic inference. Mol Biol Evol. 1999;16(8):1114-6. https://doi.org/10.1093/oxfordjournals. molbev.a026201.

80. Voorrips RE. MapChart: software for the graphical presentation of linkage maps and QTLs. J Hered. 2002;93(1):77-8. https://doi.org/10.1093/jhered/ 93.1.77.

81. Schilling S, Kennedy A, Pan S, Jermiin LS, Melzer R. Genome-wide analysis of MIKC-type MADS-box genes in wheat: pervasive duplications, functional conservation and putative neofunctionalization. New Phytol. 2020;225(1): 511-29. https://doi.org/10.1111/nph.16122.

82. Fan K, Yuan S, Chen J, Chen Y, Li Z, Lin W, et al. Molecular evolution and lineage-specific expansion of the PP2C family in Zea mays. Planta. 2019; 250(5):1521-38. https://doi.org/10.1007/s00425-019-03243-x.

83. Kong X, Lv W, Zhang D, Jiang S, Zhang S, Li D. Genome-wide identification and analysis of expression profiles of maize mitogen-activated protein kinase kinase kinase. PLoS One. 2013;8(2):e57714. https://doi.org/10.1371/ journal.pone.0057714

84. Gu Z, Cavalcanti A, Chen FC, Bouman P, Li WH. Extent of gene duplication in the genomes of Drosophila, nematode, and yeast. Mol Biol Evol. 2002;19(3):256-62. https://doi.org/10.1093/oxfordjournals. molbev.a004079.

85. Krzywinski M, Schein J, Birol I, Connors J, Gascoyne R, Horsman D, et al. Circos: an information aesthetic for comparative genomics. Genome Res. 2009;19(9):1639-45. https://doi.org/10.1101/gr.092759.109.

86. Chen C, Chen H, Zhang Y, Thomas HR, Frank MH, He Y, et al. TBtools: an integrative toolkit developed for interactive analyses of big biological data Mol Plant. 2020;13(8):1194-202. https://doi.org/10.1016/j.molp.2020.06.009.

87. Hurst LD. The Ka/Ks ratio: diagnosing the form of sequence evolution Trends Genet. 2002;18(9):486-7. https://doi.org/10.1016/S0168-9525(02)02 722-1.

88. Bailey TL, Boden M, Buske FA, Frith M, Grant CE, Clementi L, et al. MEME SUITE: tools for motif discovery and searching. Nucleic Acids Res. 2009; 37(Web Server):W202-8. https://doi.org/10.1093/nar/gkp335.

89. Lescot $M$, Déhais $P$, Thijs $G$, Marchal $K$, Moreau $Y$, Van de Peer $Y$, et al. PlantCARE, a database of plant cis-acting regulatory elements and a portal to tools for in silico analysis of promoter sequences. Nucleic Acids Res. 2002;30(1):325-7. https://doi.org/10.1093/nar/30.1.325.

90. Beier S, Thiel T, Münch T, Scholz U, Mascher M. MISA-web: a web server for microsatellite prediction. Bioinformatics. 2017;33(16):2583-5. https://doi. org/10.1093/bioinformatics/btx198.

91. Untergasser A, Cutcutache I, Koressaar T, Ye J, Faircloth BC, Remm M, et al. Primer3--new capabilities and interfaces. Nucleic Acids Res. 2012;40(15):e115. https://doi.org/10.1093/nar/gks596.

92. Rotmistrovsky K, Jang W, Schuler GD. A web server for performing electronic PCR. Nucleic Acids Res. 2004;32:108-12.

93. Kumar A, Sharma M, Gahlaut V, Nagaraju M, Chaudhary S, Kumar A, et al. Genome-wide identification, characterization, and expression profiling of SPX gene family in wheat. Int J Biol Macromol. 2019;140:17-32. https://doi. org/10.1016/j.ijbiomac.2019.08.105.

94. Kozomara A, Griffiths-Jones S. miRBase: annotating high confidence microRNAs using deep sequencing data. Nucleic Acids Res. 2014;42(Database issue):D68-73. https://doi.org/10.1093/nar/ gkt1181.

95. Borrill P, Ramirez-Gonzalez R, Uauy C. expVIP: a customizable RNA-seq data analysis and visualization platform. Plant Physiol. 2016;170(4):2172-86. https://doi.org/10.1104/pp.15.01667.

96. Wang R, Ma J, Zhang Q, Wu C, Zhao H, Wu Y, et al. Genome-wide identification and expression profiling of glutathione transferase gene family under multiple stresses and hormone treatments in wheat (Triticum aestivum L.). BMC Genomics. 2019;20(1):986.

97. Zhang XZ, Zheng WJ, Cao XY, Cui XY, Zhao SP, Yu TF, et al. Genomic analysis of stress associated proteins in soybean and the role of GmSAP16 in abiotic stress responses in Arabidopsis and 
soybean. Front Plant Sci. 2019;10:1453. https://doi.org/10.3389/fpls.201 9.01453 .

98. Clough SJ, Bent AF. Floral dip: a simplified method for agrobacteriummediated transformation of Arabidopsis thaliana. Plant J. 1998;16(6):735-43. https://doi.org/10.1046/j.1365-313x.1998.00343.x.

99. Udvardi MK, Czechowski T, Scheible WR. Eleven golden rules of quantitative RT-PCR. Plant Cell. 2008;20(7):1736-7. https://doi.org/10.1105/tpc.108.061143.

\section{Publisher's Note}

Springer Nature remains neutral with regard to jurisdictional claims in published maps and institutional affiliations.

Ready to submit your research? Choose BMC and benefit from:

- fast, convenient online submission

- thorough peer review by experienced researchers in your field

- rapid publication on acceptance

- support for research data, including large and complex data types

- gold Open Access which fosters wider collaboration and increased citations

- maximum visibility for your research: over $100 \mathrm{M}$ website views per year

At BMC, research is always in progress.

Learn more biomedcentral.com/submissions 